\title{
Peucedanum japonicum Thunberg and Its Active Components Mitigate Oxidative Stress, Inflammation and Apoptosis after Urban Particulate Matter-Induced Ocular Surface Damage
}

\author{
Wan Seok Kang ${ }^{1}$, Hakjoon Choi ${ }^{1}$, Ki Hoon Lee ${ }^{1}$, Eun Kim ${ }^{1}$, Kyeong Jo Kim ${ }^{1}$, Jin Seok Kim ${ }^{1}$, Chang-Su Na ${ }^{2} \mathbb{D}$ \\ and Sunoh $\mathrm{Kim}^{1, * \mathbb{D}}$ \\ 1 Central R\&D Center, B\&Tech Co., Ltd., Gwangju 61239, Korea; kws2602@hanmail.net (W.S.K.); \\ ohchj12@naver.com (H.C.); leekh3261@daum.net (K.H.L.); rubsang84@gmail.com (E.K.); \\ kkkjzzang@nate.com (K.J.K.); keki2000@naver.com (J.S.K.) \\ 2 College of Korean Medicine, Dongshin University, Naju-si 58245, Korea; nakugi@hanmail.net \\ * Correspondence: sunoh@korea.ac.kr; Tel./Fax: +82-(62)-528-2201
}

\section{check for} updates

Citation: Kang, W.S.; Choi, H.; Lee, K.H.; Kim, E.; Kim, K.J.; Kim, J.S.; Na, C.-S.; Kim, S. Peucedanum japonicum Thunberg and Its Active Components Mitigate Oxidative Stress,

Inflammation and Apoptosis after Urban Particulate Matter-Induced Ocular Surface Damage. Antioxidants 2021, 10, 1717. https://doi.org/ $10.3390 /$ antiox 10111717

Academic Editor: Gunhyuk Park

Received: 13 September 2021

Accepted: 26 October 2021

Published: 28 October 2021

Publisher's Note: MDPI stays neutral with regard to jurisdictional claims in published maps and institutional affiliations.

Copyright: (c) 2021 by the authors. Licensee MDPI, Basel, Switzerland. This article is an open access article distributed under the terms and conditions of the Creative Commons Attribution (CC BY) license (https:// creativecommons.org/licenses/by/ $4.0 /)$.

\begin{abstract}
We previously demonstrated that urban particulate matter (UPM) exposure decreases the migration activity and survival of human corneal epithelial cells (HCECs). Herein, we investigated the potential to improve the corneal wound-healing ability of Peucedanum japonicum Thunb. leaf extract (PJE) and its active components on UPM-induced ocular surface damage in vitro and in vivo. PJE effectively assisted wound healing without altering HCEC survival and enhanced catalase (CAT), heme oxygenase 1 (HO1) and glutathione peroxidase 1 (GPX1) antioxidant gene expression. A corneal wound was uniformly induced on the right eye in all experimental animals and divided into eight groups such as two control groups (wounded right eye group-NR and non-wounded left eye group-NL), UPM treated group and PJEs $(25,50,100,200,400 \mathrm{mg} / \mathrm{kg})$ treated groups. Corneal abrasion model rats exposed to UPM showed delayed wound healing compared to unexposed rats, but wound healing was dose-dependently enhanced by PJE oral administration. Seventy-two hours after wound generation, inflammatory cells, apoptotic cells and interleukin-6 (IL-6) expression were increased substantially after UPM exposure, but PJE treatment significantly reduced the wound to an almost normal level while enhancing re-epithelialization without changing corneal thickness. Next, we tried to identify the key molecules for enhancing wound healing through fractionation. The major compounds in the fraction, confirmed by high-performance liquid chromatography (HPLC), were chlorogenic acid (CA), neochlorogenic acid (NCA) and cryptochlorogenic acid (CCA). Each type of CA isomers showed slightly different half maximal effective (EC50) and maximal effective (ECmax) concentrations, and their mixtures synergistically enhanced HCEC migration. Thus, corneal abrasion wound recovery after UPM exposure improved after PJE treatment, and the active PJE components were identified, providing an important basis to develop therapeutics for ocular surface damage using PJE.
\end{abstract}

Keywords: urban particulate matter (UPM); Peucedanum japonicum Thunberg; corneal epithelial cells; wound healing; antioxidant; inflammation

\section{Introduction}

Reactive oxygen species (ROS), spontaneously generated by metabolic enzymes, regulate cellular response as signal molecules. However, excessive ROS have cellular toxicity and cause various diseases such as cancer, brain diseases, heart diseases and autoimmune diseases by DNA denaturation, cell membrane degradation and protein degradation [1]. The cumulated data demonstrate that particulate matter (PM) has toxic effects on cardiovascular systems as well as eyes, skin and respiratory systems [2-4]. Many researchers have revealed through in vitro studies that PM exposure induces migratory activity dysfunction and a decrease in corneal survival through oxidative stress, inflammation and 
autophagy [5-8]. A study demonstrated that oxidative stress induced by both PM2.5 and PM10 collected from road dust are not different, but the cellular responses are dependent on the concentration and solubility [9]. Dry eye disease-like symptoms reported in animal studies using PM2.5 and PM10 are not largely different [5,10], and the progression of the symptoms is probably more dependent on the inflammatory response [11]. In our previous study, the adverse effects of urban particulate matter (UPM) were widely explored in the cornea, conjunctiva and retina in a time-dependent manner [12]. Our results demonstrated that long-term exposure of the eyes to UPM induces dry eye-like symptoms, inflammatory responses and deleterious structural changes in the cornea, conjunctiva and retina. Based on these studies, the cornea has become the major target for the development of a protective agent against external risks because it is constantly exposed to the environment and easily injured. Additional defects caused by UPM exposure, including tear film instability, presbyopia, allergic conjunctivitis, toxicity, oxidative stress and inflammation, have been reported in in vivo studies [13-16]. These defects are easily induced by short-term exposure to UPM, even though the exposure methods and sources of UPM are different among different studies $[5,10,17,18]$.

Corneal abrasion is a type of injury that commonly occurs on the corneal surface and affects nearly $2 \%$ of the population annually [19]. The causes of this kind of injury vary widely, from shallow scratches from daily activities such as rubbing, makeup, applying contact lenses and dust to severe wounds such as surgery and accidents [19-21]. After minor injury, the corneal epithelium rapidly recovers within $1 \sim 2$ days due to the migration and proliferation of epithelial cells [22,23]. However, normal wound healing can be delayed by the depth and nature of injury or metabolic disorders and result in scarring of the tissue or major corneal issues $[19,21]$. Furthermore, UPM can cause delayed corneal wound healing, as described above, by well-studied mechanisms [24]. However, the direct effects of UPM on the wound healing process have not been sufficiently investigated because most studies have performed only in vitro experiments. Some studies have shown enhanced wound healing using numerous molecules, but although certain therapeutic strategies have been suggested, such as increasing the migration and proliferation of epithelial cells, no agent has been successfully identified [25-28]. In addition, some agents require repeated applications due to their low bioavailability, which presents a limitation $[29,30]$. Thus, efforts to discover a new approach to improve delayed wound healing after exposure to disturbing factors, such as UPM, are necessary. Therefore, this study was designed to investigate the effects of UPM on corneal wound healing and find a new protective agent. Such an agent should be safe, easy to apply and have multiple functions, such as enhancing the migratory activity of epithelial cells and having antioxidative and antiinflammatory properties. Herbal extracts can be a solution due to their safety and multiple protective functions.

Peucedanum japonicum Thunb. (family Apiaceae) is traditionally used as a vegetable in the East Asia region, but it is sometimes used as a medicine for headaches, colds, neuralgia, rheumatoid arthritis and other inflammatory diseases [31,32]. P. japonicum has been reported to contain coumarins, phenolic compounds, chromones, polyacetylenes, inositols and steroid glycosides [33,34]. P. japonicum has anti-obesity [35,36], antiplatelet [37,38], antiallergic [39,40], antioxidative [41,42] and anti-inflammatory properties [30]. Chlorogenic acid (CA) and its isomers, neochlorogenic acid (NCA) and cryptochlorogenic acid (CCA), are known as its major constituents, and their antioxidative functions have been reported [41]. Because CAs are abundant in foods, especially coffee, they have attracted a lot of attention, but they also have other well-established beneficial effects on cardiovascular, metabolic, neuronal and hepatic diseases, even cancer [43]. However, the protective effects of the CAs found in P. japonicum on wound healing, especially after UPM exposure, are not well studied. Therefore, the leaf extract of $P$. japonicum (PJE) was assessed for its effect on the wound healing process, and its mechanism and active molecules were investigated in this study. 


\section{Materials and Methods}

\subsection{Reagents}

In this study, we used commercially available UPM (Standard Reference Material ${ }^{\circledR}$ 1648a (SRM1648a), National Institute of Standards Technology, Gaithersburg, MD, USA). The detailed information (certificate of analysis) on SRM1648a can be accessed via this link (Material details of SRM1648a. Available online: https: / / www-s.nist.gov/srmors/view detail.cfm?srm=1648a (accessed on 21 October 2021)).

\subsection{Sample Preparation and HPLC Analysis}

In order to ensure the validation of PJE and reproducibility of efficacy, P. japonicum Thunb., harvested by selecting the region $\left(34^{\circ} 35^{\prime} 24.2^{\prime \prime} \mathrm{N}, 126^{\circ} 48^{\prime} 09.3^{\prime \prime}\right.$ E, Gangjin-gun, Jeollanamdo, Korea) and season (September), was used in this study. The branches and roots were removed, and only the leaf part was selected and dried in the hot air oven at $45{ }^{\circ} \mathrm{C}$ for $48 \mathrm{~h}$. The dried leaves of $P$. japonicum Thunb. (1 kg) were extracted using 20 volumes of water at $100{ }^{\circ} \mathrm{C}$ for $4 \mathrm{~h}$. The extracted solution was then filtered, concentrated with an evaporator under vacuum and spray dried, which gave the PJE sample. For solvent fractionation, the dried water extract (PJE, $100 \mathrm{~g}$ ) was resuspended in water and partitioned with $n$-hexane $(3 \times 1 \mathrm{~L})$, chloroform $\left(\mathrm{CHCl}_{3} ; 3 \times 1 \mathrm{~L}\right)$, ethyl acetate $($ EtOAc; $3 \times 1 \mathrm{~L})$ and $n$-butanol $(\mathrm{BuOH} ; 3 \times 1 \mathrm{~L})$ (Figure 1). The samples were dissolved in $50 \%$ methanol, sonicated for $20 \mathrm{~min}$ and then analyzed using an Agilent 1260 HPLC system (Agilent Technologies, Palo Alto, CA, USA) equipped with an Eclipse XDB-C18 column $(4.6 \times 250$ $\mathrm{mm}, 5 \mu \mathrm{m})$. The temperature of the column oven was maintained at $40{ }^{\circ} \mathrm{C}$. The mobile phase for liquid chromatography (LC) consisted of $0.1 \%(v / v)$ formic acid in water (solvent A) and 70\% $(v / v)$ acetonitrile in water (solvent B) and was applied as follows: 0-20 min, 2-12.5\% (B); 20-30 min, 12.5-13\% (B); 30-50 min, 13-40\% (B); and 50-51 min, 40-2\% (B), followed by re-equilibration with $2 \%$ (B) for $51-55 \mathrm{~min}$ at a flow rate of $1 \mathrm{~mL} / \mathrm{min}$ and an injection volume of $10 \mu \mathrm{L}$. The detection wavelength was set to $330 \mathrm{~nm}$. Quantitative HPLC analysis was replicated three times.

\subsection{Open Column Chromatography and Thin-Layer Chromatography (TLC) Analysis}

The $\mathrm{H}_{2} \mathrm{O}$ fraction $(20 \mathrm{~g})$ was separated with an HP-20 open column $(6.5 \times 52 \mathrm{~cm}$; 250-850 $\mu \mathrm{m}$ particle size, IONTEC, Seongnam, Republic of Korea) and eluted with $\mathrm{H}_{2} \mathrm{O} /$ $\mathrm{MeOH}$ (a stepwise system of 10:0, 8:2, 6:4, 2:8, 0:10 v/v, each $8 \mathrm{~L}$ ). Each obtained fraction was analyzed using the HPLC system. All fractions obtained from the purification process were spotted on silica gel for TLC analysis (silica gel 60 F254, $0.25 \mathrm{~mm}$ thickness; Merck) and run in a solvent system composed of $n-\mathrm{BuOH} /$ acetic acid $/ \mathrm{H}_{2} \mathrm{O}(4: 1: 2, v / v / v)$ in a TLC chamber at room temperature. The purities of the fractionated compounds were determined by UV visualization after spraying with $1 \%$ cerium sulfate. All fractionation steps and TLC analysis images are illustrated in Figure 1.

\subsection{HCEC Culture}

The simian virus 40 (SV40)-transformed HCE cell line (RIKEN BioSource Center, Tokyo, Japan) was cultured in Dulbecco's modified Eagle's medium/Ham's F-12 (DMEM/F12) (Welgene, Daegu, Korea) supplemented with $5 \%$ fetal bovine serum, $5 \mu \mathrm{g} / \mathrm{mL}$ insulin, $10 \mathrm{ng} / \mathrm{mL}$ epidermal growth factor and $0.5 \%$ dimethyl sulfoxide (DMSO).

\subsection{Cell Viability}

Cell viability was evaluated with a 3-(4,5-dimethylthiazol-2-yl)-2,5-diphenyltetrazolium bromide (MTT) assay. Cells $\left(2 \times 10^{4}\right.$ cells / well) were plated in 96-well plates, and after $24 \mathrm{~h}$, the cells were treated with $100 \mu \mathrm{g} / \mathrm{mL}$ UPM and various concentrations of PJE (1-300 $\mu \mathrm{g} / \mathrm{mL})$, PJE fractions $(0.1-30 \mu \mathrm{g} / \mathrm{mL})$ or CAs $(0.028-8.46 \mu \mathrm{M})$ for $48 \mathrm{~h}$. The cells were then incubated with $0.5 \mathrm{mg} / \mathrm{mL}$ MTT solution for $2 \mathrm{~h}$, and the generated formazan was dissolved in DMSO. Cell viability was measured with a microplate reader (BioTek, Winooski, VT, USA) at $540 \mathrm{~nm}$. 


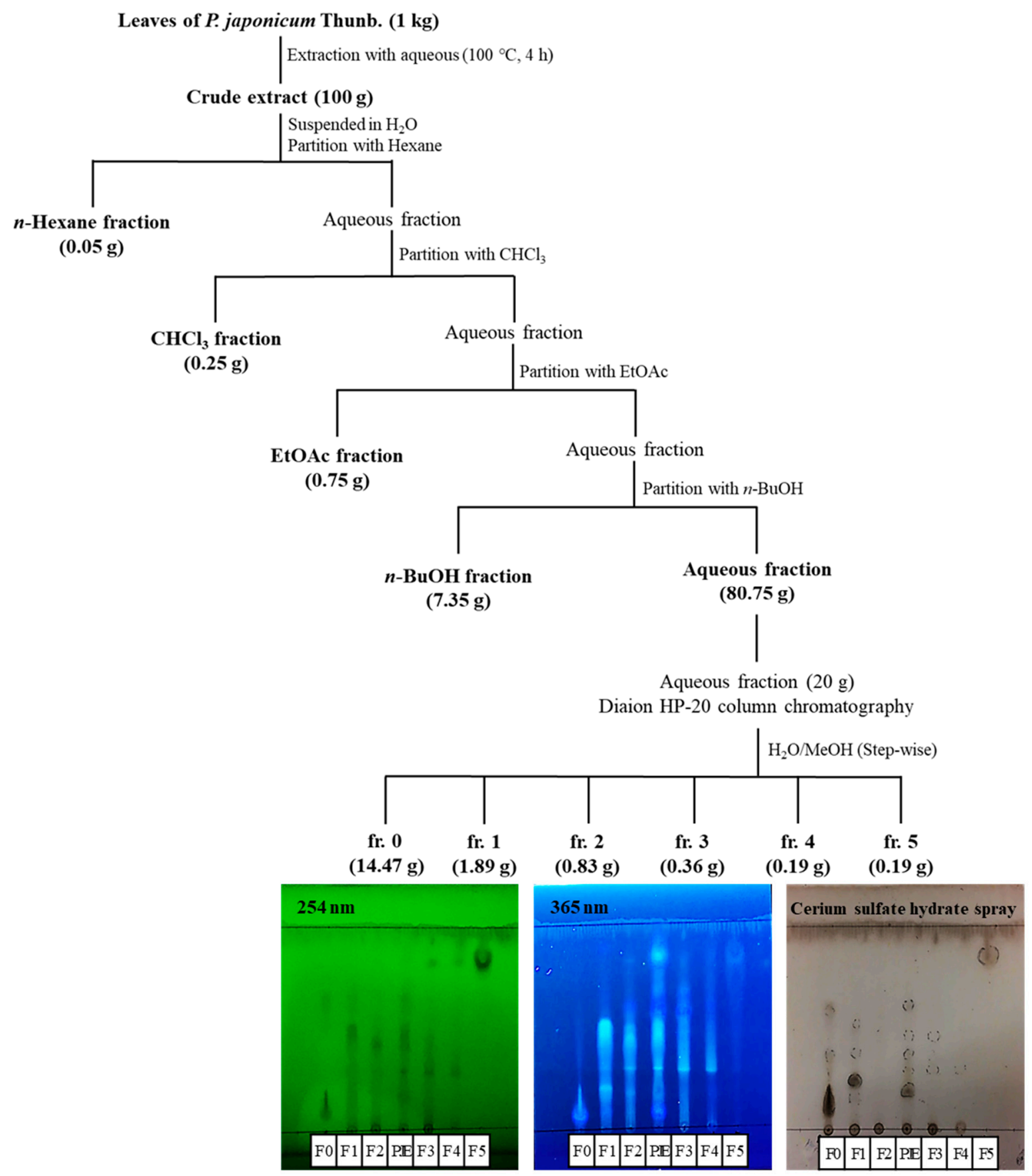

Figure 1. Scheme of PJE fractionation by solvent-solvent extraction and open column chromatography. TLC analysis images are also presented.

\subsection{Scratch Wound Healing Assay}

The scratch wound healing assay was performed to assess the effects of UPM on the migration of HCECs as previously reported [12]. Briefly, cells were preincubated with $100 \mu \mathrm{g} / \mathrm{mL}$ UPM and 1-300 $\mu \mathrm{g} / \mathrm{mL}$ PJE suspended in DMEM/F-12 medium without supplements for $24 \mathrm{~h}$. Then, a steady line (scratch) was created using a sterile $200 \mu \mathrm{L}$ pipette tip across the cells on the bottom of the culture dish. The culture media was replaced with fresh media with the appropriate dose of PJE, and photographs were taken at 0 and $24 \mathrm{~h}$ using a microscope equipped with a digital camera (Leica Microsystems, Wetzlar, Germany). The migration rate was calculated by relative comparison of the closed area at $24 \mathrm{~h}$ with the area at $0 \mathrm{~h}$, as measured by ImageJ software (National Institutes of Health, 
Bethesda, MD, USA). The assay was repeated three times, and each area was measured at least three times. The PJE fractions and their major compounds, CA (Sigma-Aldrich, St. Louis, MO, USA), NCA (Sigma-Aldrich) and CCA (Sigma-Aldrich), were also assessed with the same method described above. The half maximal effective concentration $\left(\mathrm{EC}_{50}\right)$ and maximal effective concentration $\left(\mathrm{EC}_{\max }\right)$ of each $\mathrm{CA}$ or CA mixture were calculated using the software program GraphPad Prism 5 version 5.01 for Windows (GraphPad, Inc., San Diego, CA, USA).

\subsection{Real-Time Polymerase Chain Reaction (PCR)}

After the wound healing assay, the cells were lysed with TRIzol reagent (Invitrogen, Carlsbad, CA, USA) to extract total RNA, and $2 \mu \mathrm{g}$ of RNA was reverse-transcribed with MMLV reverse transcriptase (Enzynomics, Daejeon, Korea) according to the manufacturer's instructions. The sequences of the primers were as follows: for human superoxide dismutase type 1 (SOD1) (NM_000454.5): sense, 5-GGTGGGCCAAAGGATGAAGAG-3 and antisense, 5-CCACAAGCCAAACGACTTCC-3; for human CAT (NM_001752.4): sense, 5TGGAGCTGGTAACCCAGTAGG-3 and antisense, 5-CCTTTGCCTTGGAGTATTTGGTA-3; for human HO1 (NM_002133.3): sense, 5-AAGACTGCGTTCCTGCTCAAC-3 and antisense, 5-AAAGCCCTACAGCAACTGTCG-3; for human glutathione peroxidase 1 (GPX1) (NM_000581.4): sense, 5-CAGTCGGTGTATGCCTTCTCG-3 and antisense, 5-GAGGGACG CCACATTCTCG-3; and for human $\beta$-actin (NM_001101.5): sense, 5-CTCACCCTGAAGTA CCCCATC-3 and antisense, 5-GGATAGCACAGCCTGGATAGCA-3. PCR was performed for 45 cycles under the following conditions: denaturation at $95{ }^{\circ} \mathrm{C}$ for $20 \mathrm{~s}$, annealing at $58{ }^{\circ} \mathrm{C}$ for $20 \mathrm{~s}$ and extension at $72{ }^{\circ} \mathrm{C}$ for $20 \mathrm{~s}$ using a CFX96 (Bio-Rad, Hercules, CA, USA) with RbTaq qPCR $2 \times$ PreMIX (Enzynomics, Daejeon, Korea). RNA levels were normalized to that of $\beta$-actin.

\subsection{Animals}

Five-week-old male Sprague-Dawley (S-D) rats were purchased from Samtako Animal, Inc. (Osan, Korea). All experimental procedures were conducted in accordance with the relevant guidelines for the care of experimental animals and approved by the Institutional Animal Care and Use Committee (IACUC) of Bioresources and Technology (B\&Tech) Co., Ltd., Republic of Korea (B\&Tech) (approval number: BT-003-2020). Animals were quarantined before the experiment and allowed to adapt to the environment for 1 week. All participating rats had normal ocular surfaces as evidenced with a stereomicroscope.

\subsection{Animal Grouping and Dosing}

UPM was dissolved in phosphate-buffered saline (PBS) to prepare a $5 \mathrm{mg} / \mathrm{mL}$ eye drop solution. The solution was stored in glass bottles at $4{ }^{\circ} \mathrm{C}$ and used within one week. The rats were randomly divided into 8 groups $(n=6 /$ group), namely, the control groups (wounded right eye group-NR and non-wounded left eye group-NL), UPMtreated group (UPM), $25 \mathrm{mg} / \mathrm{kg}$ PJE-treated group (25), $50 \mathrm{mg} / \mathrm{kg}$ PJE-treated group (50), $100 \mathrm{mg} / \mathrm{kg}$ PJE-treated group (100), $200 \mathrm{mg} / \mathrm{kg}$ PJE-treated group (200) and $400 \mathrm{mg} / \mathrm{kg}$ PJE-treated group (400). The left eye of the normal group was used as the normal eye (NL), while the right eye was used as the wound control. All PJE and UPM groups received $10 \mu \mathrm{L}$ of UPM solution as an eye drop into the right eye 4 times per day. Each dose of PJE was orally administered once a day. UPM and PJE administration began 5 days before wound generation and continued until the end of the experiment. For wound generation, all rats were anesthetized by intraperitoneal injection of a mixture of ketamine $(50 \mathrm{mg} / \mathrm{kg})$ and xylazine $(5 \mathrm{mg} / \mathrm{kg})$, and a $4 \mathrm{~mm}$ diameter wound was created on the right eye with an Alger brush rotating burr tool (The Alger Company Inc., Lago Vista, TX, USA). The wounded corneas were stained with fluorescein solution, and images were captured at 0,8 , $16,24,36,48$ and $72 \mathrm{~h}$. Then, the animals were sacrificed, and the eyeballs were collected for further analysis. 


\subsection{Fluorescein Staining}

Fluorescein staining, tear volume and tear break-up time (TBUT) were performed as previously described [12]. Briefly, the wounded area was stained with $2 \mu \mathrm{L}$ of $0.5 \%$ sodium fluorescein solution, and images were captured with a funduscope with an integrated fiber optic light source equipped with a low light fluorescence camera (OcuScience, Henderson, $\mathrm{NV}$, USA). The time-dependent changes in wounded area were calculated and compared with the area at $0 \mathrm{~h}$, which was measured by ImageJ software (National Institutes of Health, Bethesda, MD, USA).

\subsection{Hematoxylin and Eosin (HEE) Staining}

Eyeballs were fixed for $48 \mathrm{~h}$ in $10 \%$ buffered formalin. Then, they were coronally bisected to separate the cornea from the retinal region. The corneas were embedded in paraffin and sliced into $4 \mu \mathrm{m}$ thick sections. The sections were deparaffinized and rehydrated using standard techniques and stained with Mayer's hematoxylin and 1\% eosin. The stained sections were dehydrated and cleared with xylene. Mounting was performed using Canada balsam and the sections were observed under a light microscope (Nikon, Tokyo, Japan). The immune cells' infiltration in the central and lateral cornea was calculated by measuring densities of nuclei. Covered area by re-epithelialization compared to whole corneal surface area and cell attached area in inner cornea were also calculated. All histological changes were quantified by ImageJ software (National Institutes of Health, Bethesda, MD, USA).

\subsection{Terminal Deoxynucleotidyl Transferase dUTP Nick End Labeling (TUNEL) Staining}

The number of apoptotic cells was determined with an In Situ Cell Death Detection kit (Sigma, St Louis, MO, USA) following the manufacturer's instruction. Tissue sections were stained with DAPI containing mounting medium to visualize all nuclei. The apoptotic cells were counted under a fluorescence microscope, and their number in three different regions of each section were used for analysis. Densities of the apoptotic cells were analyzed by ImageJ software (National Institutes of Health, Bethesda, MD, USA).

\subsection{Immunohistochemical Staining}

The interleukin-6 (IL-6) in the tissue was determined by immunohistochemical staining with the anti-IL6 antibody (Abcam, Cambridge, MA, USA) and a detection kit (Dako, Carpinteria, CA, USA) including a secondary antibody. All procedures were performed according to the manufacturers' recommendations. Nuclei were visualized by hematoxylin counter-staining. The stained sections were observed under a light microscope (Nikon, Tokyo, Japan), and images were obtained. Densities of the IL-6 were analyzed by Image J software (National Institutes of Health, Bethesda, MD, USA).

\subsection{Statistical Analysis}

All quantitative results were presented as the mean \pm standard deviation (SD).

Statistical significances were tested using Student's $t$-test or two-way analysis of variance (ANOVA) with GraphPad Prism 5 version 5.01 for Windows (GraphPad, Inc., San Diego, CA, USA), and the $p$ values under 0.05 were marked using indicators.

\section{Results}

\subsection{HPLC Analysis of the PJE}

Characterization and identification of the natural compounds in PJE were determined by HPLC. The concentrations of NCA, CA and CCA were $2.27 \pm 0.03 \mathrm{mg} / \mathrm{g}$, $2.30 \pm 0.03 \mathrm{mg} / \mathrm{g}$ and $2.57 \pm 0.04 \mathrm{mg} / \mathrm{g}$, respectively. Representative chromatograms of the NCA, CA and CCA references and their corresponding peaks in the PJE are illustrated in Figure 2. 


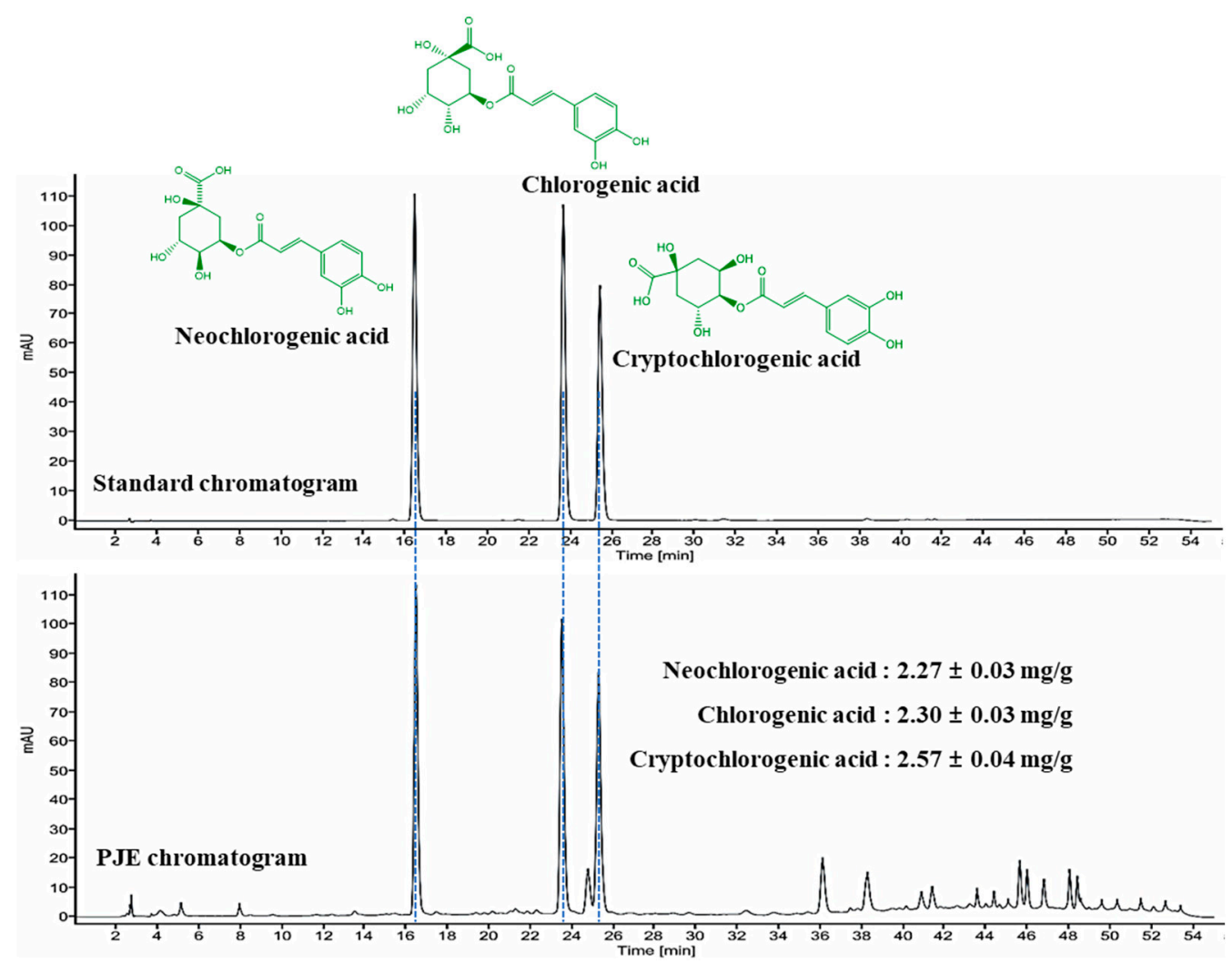

Figure 2. HPLC chromatograms of chlorogenic acid (CA), neochlorogenic acid (NCA) and cryptochlorogenic acid (CCA) as standard compounds and the P. japonicum Thunberg leaf extract (PJE).

\subsection{PJE Enhances the Migration Activity of HCECs after UPM Exposure}

Previously, UPM decreased the migration activity and survival of HCECs [12]. Many herbal extracts were screened by scratch wound healing assay (data not shown), and PJE showed beneficial effects and was selected to confirm the preventive effects and detailed mechanisms in this study. The migration activity of HCECs was decreased to $38.7 \%$ by UPM exposure compared with normal cells. PJE treatment after UPM exposure improved the migration activity of HCECs dose-dependently until $100 \mu \mathrm{g} / \mathrm{mL}$ PJE, and the maximal migration reached $59.3 \%$ compared with that of normal cells, but at higher concentrations, the migration was slightly decreased, even though it was still higher than that of UPM-only exposed cells (Figure 3A,B). Cell survival was decreased by UPM exposure and was not changed by PJE treatment (Figure 3C).

\subsection{PJE Increases Antioxidative Gene Expression in HCECs after UPM Exposure}

One of the major causes of migration activity dysfunction in HCECs is oxidative stress. The messenger RNA expression of antioxidative genes in PJE-treated cells was analyzed to confirm whether the preventive effect of PJE affected antioxidant activity. The expression of SOD1 was decreased 0.84 -fold by UPM but was not changed by PJE treatment (Figure 4A). CAT expression was also decreased to 0.80 -fold by UPM but increased by PJE treatment, which showed a maximal increase to 1.13 -fold and the same at $10 \mu \mathrm{g} / \mathrm{mL}$ to $300 \mu \mathrm{g} / \mathrm{mL}$ PJE (Figure 4B). HO1 expression was not significantly changed by UPM exposure, but it increased 1.95-fold by PJE (Figure 4C). GPX1 expression was induced 1.42-fold by UPM and increased 1.87-fold by PJE treatment (Figure $4 \mathrm{D}$ ). Therefore, increased antioxidative gene expression by PJE treatment after UPM exposure may contribute to the promoted migration activity of HCECs. 
A

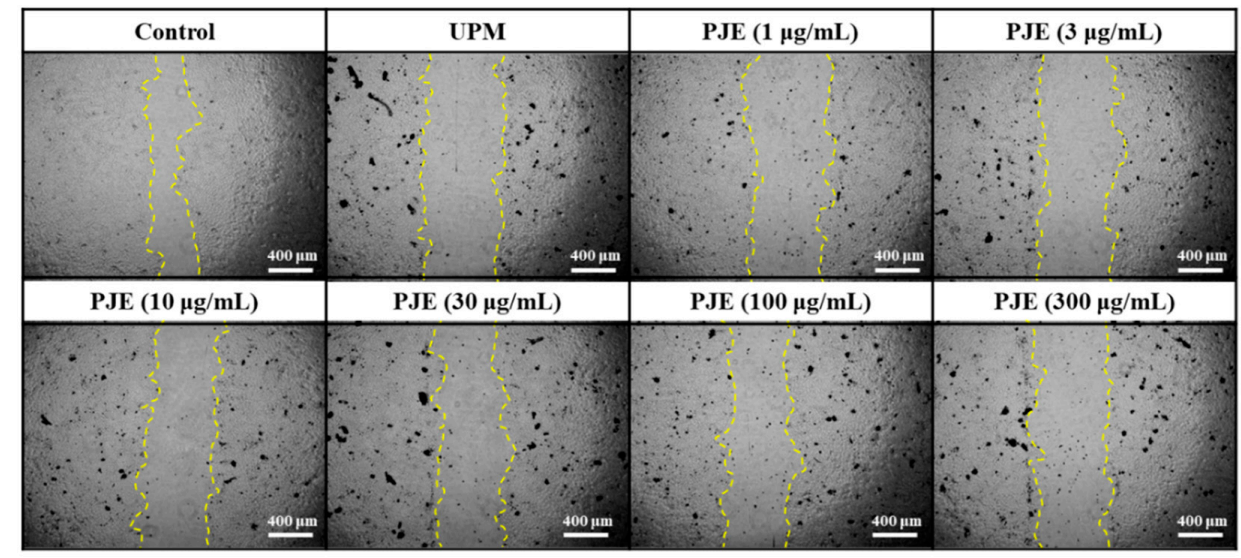

\section{B}

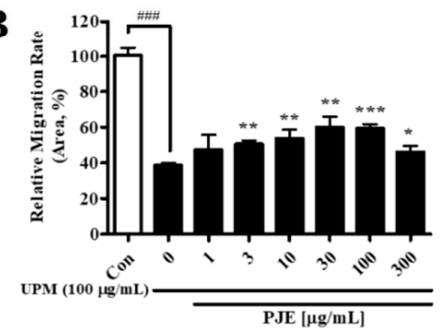

C

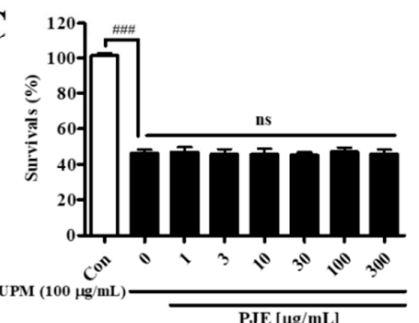

Figure 3. Effects of UPM and PJEs on the migration activity were assessed on the human corneal epithelial cells (HCECs). (A) A scratch was induced to the HCECs treated with UPM and various concentrations of PJE for $24 \mathrm{~h}$. The closed area after $24 \mathrm{~h}$ from scratch area were calculated. The scale bars indicate $400 \mu \mathrm{m}$. (B) The relative migration rates of HCECs are expressed as the means \pm SD. (C) The survival rates of HCECs are expressed as the means \pm SD. ${ }^{\# \# \# ~} p<0.001$ compared to Con; ${ }^{*} p<0.05,{ }^{* *} p<0.05,{ }^{* * *} p<0.001$ compared to $0 \mu \mathrm{g} / \mathrm{mL}$ PJE; ns, not significant.

A

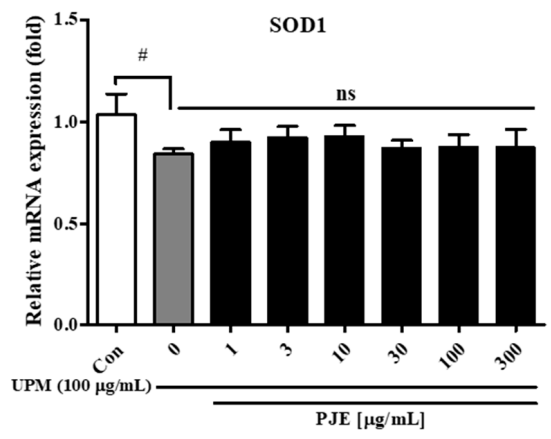

C

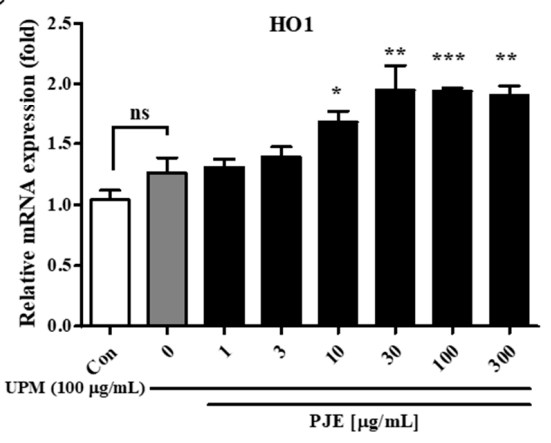

B

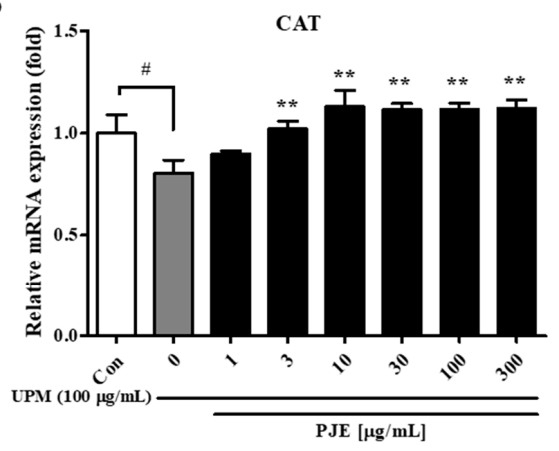

D

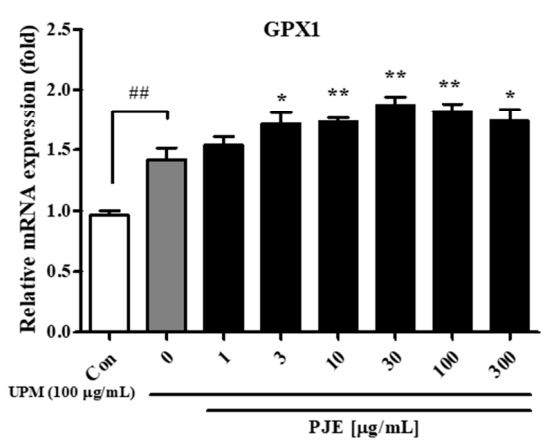

Figure 4. Effects of PJE on the mRNA expression of antioxidative genes in HCECs. After the scratch assay, the relative mRNA expression levels of (A) SOD1, (B) CAT, (C) HO1 and (D) GPX1 were analyzed, and the fold changes are presented compared with the Con as the means \pm SD. ${ }^{*} p<0.05,{ }^{\# \#} p<0.01$ compared to Con; ${ }^{*} p<0.05,{ }^{* *} p<0.01,{ }^{* * *} p<0.001$ compared to $0 \mu \mathrm{g} / \mathrm{mL}$ PJE; ns, not significant. 


\subsection{PJE Enhances Wound Healing in a Corneal Abrasion Rat Model after UPM Exposure}

Corneal epithelial wounds were generated on the right eyes of rats pretreated with various concentrations of PJE exposed to UPM, and their recovery rates were analyzed in a time-dependent manner. Healing of untreated corneal wounds was almost complete $72 \mathrm{~h}$ after wound generation (NR group), but recovery was delayed by UPM exposure (Figure 5A). The greatest difference was observed at $36 \mathrm{~h}$, with a difference between the normal and UPM groups of approximately $30 \%$ (Figure $5 B, C$ ). This difference was dosedependently decreased by PJE treatment and reached a maximum of approximately $10 \%$. At $72 \mathrm{~h}$, the area of the healed wounds in all PJE-treated groups was similar to that of the normal group, whereas the UPM group did not show sufficient recovery (Table 1).
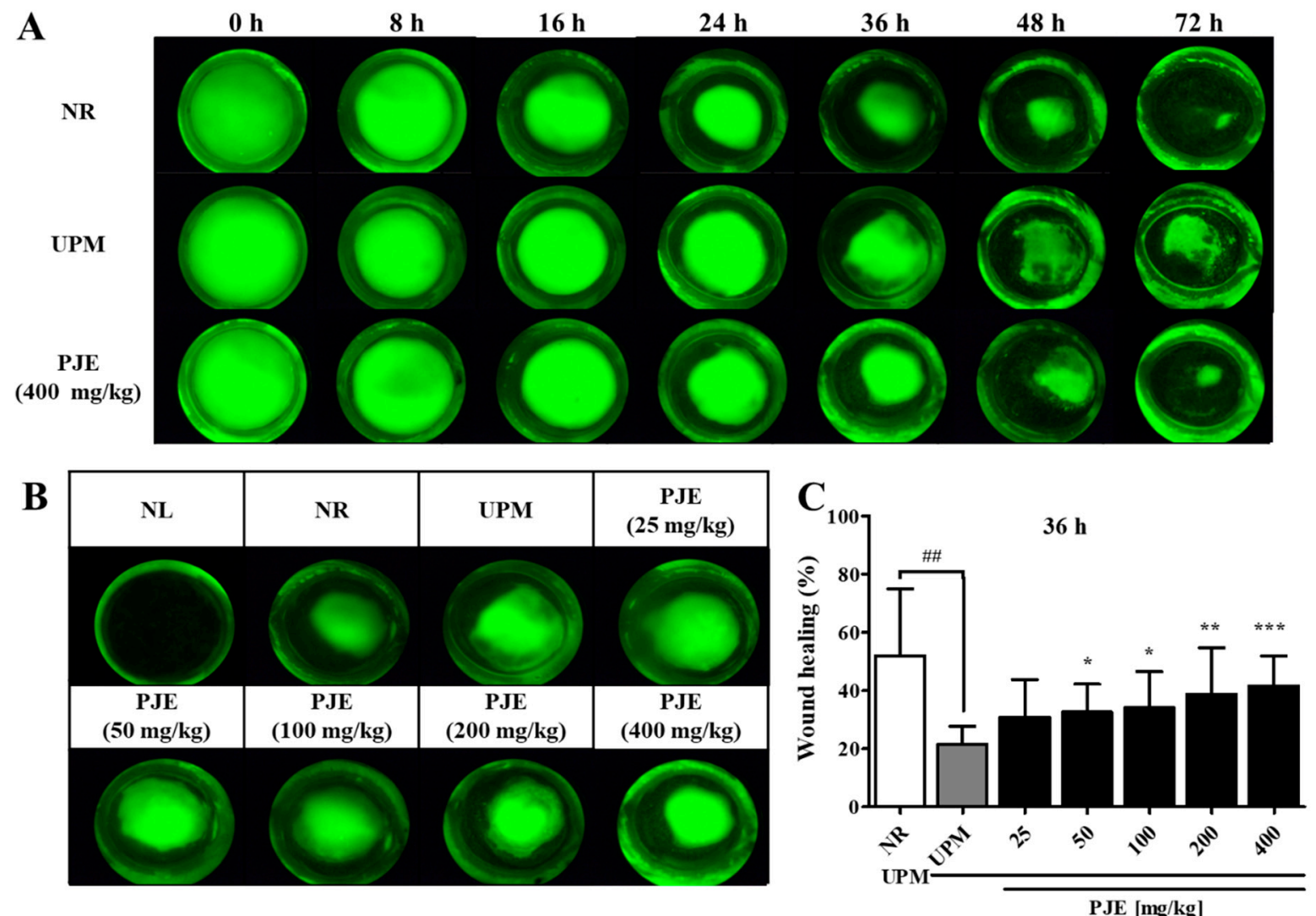

Figure 5. Effects of PJE in a corneal abrasion model after UPM exposure. PJE and UPM were used as pretreatments for 5 days, and $4 \mathrm{~mm}$ wounds were generated on the right cornea. Images were obtained at 0, 8, 16, 24, 36, 48 and $72 \mathrm{~h}$ by fluorescein staining. (A) Time course images of corneal wound healing in the normal right eye (NR, normal wound), UPM and $400 \mathrm{mg} / \mathrm{kg}$ PJE groups. (B) Representative images of each group at $36 \mathrm{~h}$. (C) The wound healing areas were calculated and are presented as the means \pm SD. ${ }^{\# \#} p<0.01$ compared to NR; ${ }^{*} p<0.05,{ }^{* *} p<0.01,{ }^{* * *} p<0.001$ compared to UPM.

Table 1. Time course observations of the changes in corneal wound healing areas after PJE treatment and UPM exposure.

\begin{tabular}{|c|c|c|c|c|c|c|c|c|c|c|c|c|c|c|c|}
\hline & & \multicolumn{2}{|c|}{$0 \mathrm{~h}$} & \multicolumn{2}{|c|}{$8 \mathrm{~h}$} & \multicolumn{2}{|c|}{$16 \mathrm{~h}$} & \multicolumn{2}{|c|}{$24 \mathrm{~h}$} & \multicolumn{2}{|c|}{$36 \mathrm{~h}$} & \multicolumn{2}{|c|}{$48 \mathrm{~h}$} & \multicolumn{2}{|c|}{$72 \mathrm{~h}$} \\
\hline & & Average & $p$ Value & Average & $p$ Value & Average & $p$ Value & Average & $p$ Value & Average & $p$ Value & Average & $p$ Value & Average & $p$ Value \\
\hline & NR & 2.7 & & 5.8 & & 24.2 & & 34.5 & & 52.0 & & 55.9 & & 81.5 & \\
\hline & UPM & 1.4 & 0.352 & 4.9 & 0.623 & 9.4 & 0.173 & 19.8 & 0.252 & 21.6 & $0.009 \# \#$ & 27.1 & $0.019 \#$ & 62.1 & $0.004 \#$ \\
\hline \multirow{5}{*}{$\begin{array}{c}\mathrm{PJE} \\
(\mathrm{mg} / \mathrm{kg})\end{array}$} & 25 & 1.7 & 0.775 & 6.9 & 0.232 & 12.4 & 0.238 & 25.6 & 0.342 & 30.9 & 0.132 & 35.1 & 0.278 & 74.6 & $0.005^{* *}$ \\
\hline & 50 & 3.3 & 0.111 & 2.1 & 0.068 & 9.4 & 0.999 & 21.6 & 0.793 & 32.6 & 0.031 * & 41.1 & 0.112 & 80.2 & 0.005 ** \\
\hline & 100 & 2.7 & 0.366 & 4.2 & 0.667 & 10.5 & 0.696 & 26.8 & 0.314 & 34.1 & $0.047^{*}$ & 44.5 & $0.027^{*}$ & 79.6 & $0.009^{* *}$ \\
\hline & 200 & 2.5 & 0.465 & 5.5 & 0.770 & 12.6 & 0.350 & 31.1 & 0.103 & 38.7 & 0.028 * & 48.1 & $0.004^{* *}$ & 80.4 & 0.003 ** \\
\hline & 400 & 1.4 & 0.954 & 5.2 & 0.821 & 12.8 & 0.104 & 27.7 & 0.204 & 41.6 & 0.001 ** & 51.6 & $0.006 * *$ & 79.2 & $<0.001^{* * *}$ \\
\hline
\end{tabular}

The mean and $p$ values are presented. ${ }^{\#} p<0.05,{ }^{\# \#} p<0.01$ compared to NR; ${ }^{*} p<0.05,{ }^{* *} p<0.01,{ }^{* * *} p<0.001$ compared to UPM. 


\subsection{Effects of PJE on Corneal Histological Changes}

The histological changes in the cornea at $72 \mathrm{~h}$ after wound generation were detected by H\&E staining. As shown in Figure 6A, the wounded normal (NR) group displayed accumulation of infiltrated inflammatory cells in the central corneal stromal region, a few immune cells were attached to the endothelial layer, and the re-epithelized cell layer was also observed. UPM exposure exacerbated the inflammatory cell infiltration and re-epithelialization during corneal recovery, while PJE treatment ameliorated these effects. Specifically, inflammatory cell infiltration was slightly increased in both the central and lateral regions of the corneas in the NR group, which was strongly increased by 3 -fold after UPM exposure and dose-dependently decreased by PJE treatment (Figure 6B,C). In the NR group, the wounded areas of the cornea were almost completely covered by epithelial cells $(87.3 \%$ coverage), but this coverage was severely delayed by UPM exposure (32.2\%) and dose-dependently enhanced by PJE treatment (Figure 6C). The area of immune cell attachment on the endothelial layer also greatly increased to $80.1 \%$ due to UPM exposure, which was significantly decreased by PJE treatment (Figure 6E). Therefore, these data demonstrated that PJE administration to treat corneal wound healing after UPM exposure significantly inhibited inflammatory cell infiltration and enhanced re-epithelialization.
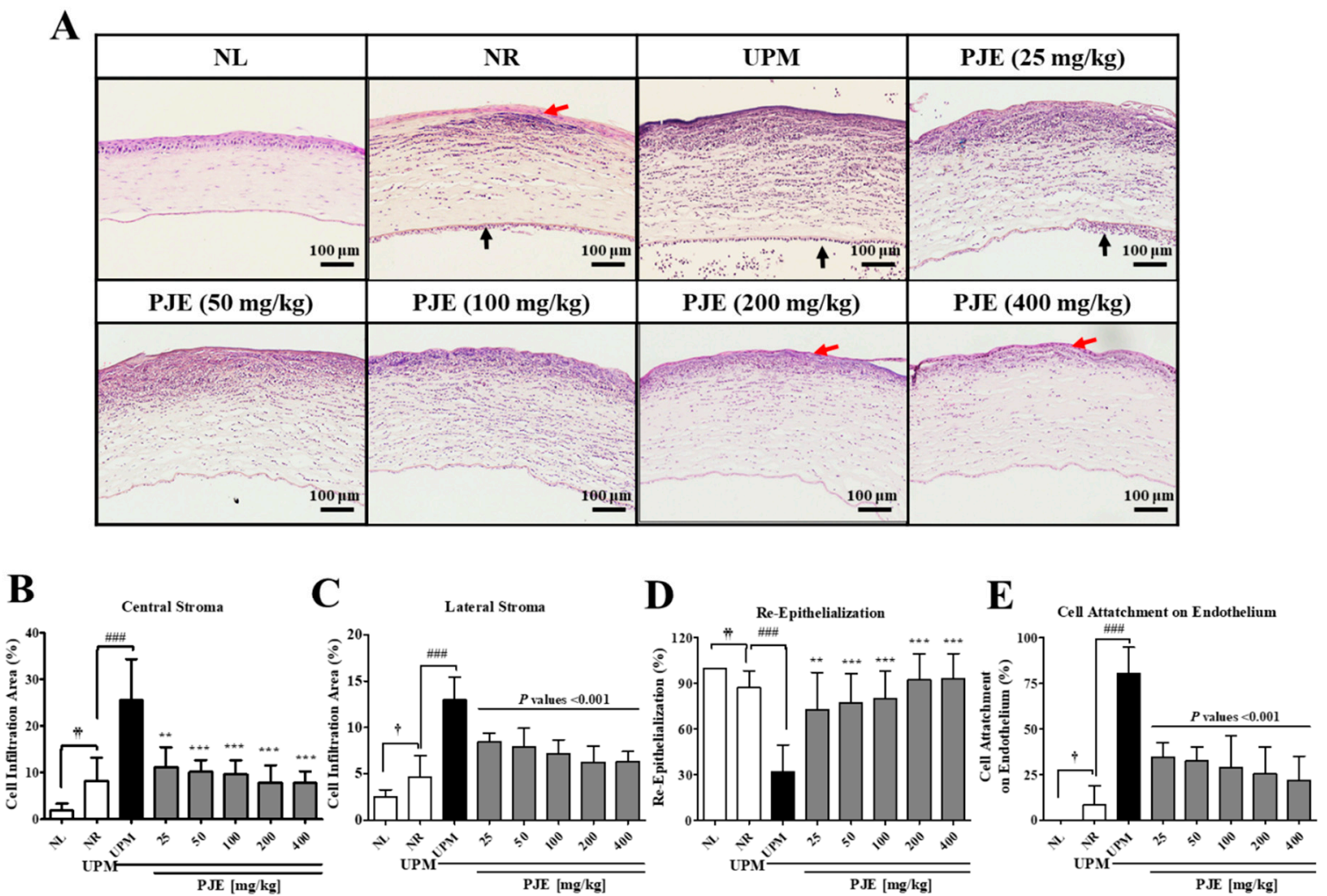

Figure 6. Histological changes during corneal wound healing after treatment with PJE and after UPM exposure. (A) Images of hematoxylin and eosin (H\&E) staining of the cornea at $72 \mathrm{~h}$ were acquired at $200 \times$ magnification, and representative images are shown. Red arrow, re-epithelialized epithelium; black arrow, cell attachment on the endothelium. The infiltration of immune cells in (B) the central stroma and (C) the lateral stroma, (D) the re-epithelialization rate and (E) cell attachment to the endothelium were calculated, and the results are presented as the means $\pm \mathrm{SD} .{ }^{\dagger} p<0.05,{ }^{\dagger+} p<0.01$ compared to NL; \#\#\# $p<0.001$ compared to NR; ${ }^{* *} p<0.01,{ }^{* * *} p<0.001$ compared to UPM.

\subsection{PJE Inhibits IL-6 Expression during Corneal Wound Healing after UPM Exposure}

The distribution of IL-6, a major player in the immune response during corneal wound healing, was analyzed by immunohistochemical staining. As shown in Figure 7A,B, IL6 -stained regions were rarely found ( $2.9 \%$ of the area) in the NR group, but these regions 
largely increased to $12.6 \%$ after UPM exposure, which was dose-dependently decreased by PJE treatment, showing results that were close to the NR level. IL-6 expression was mainly distributed in the subsuperficial region of the stroma of the wounded corneas. Corneal thickness increased significantly due to wound generation but was unchanged after UPM exposure or PJE treatment (Figure 7C).

A

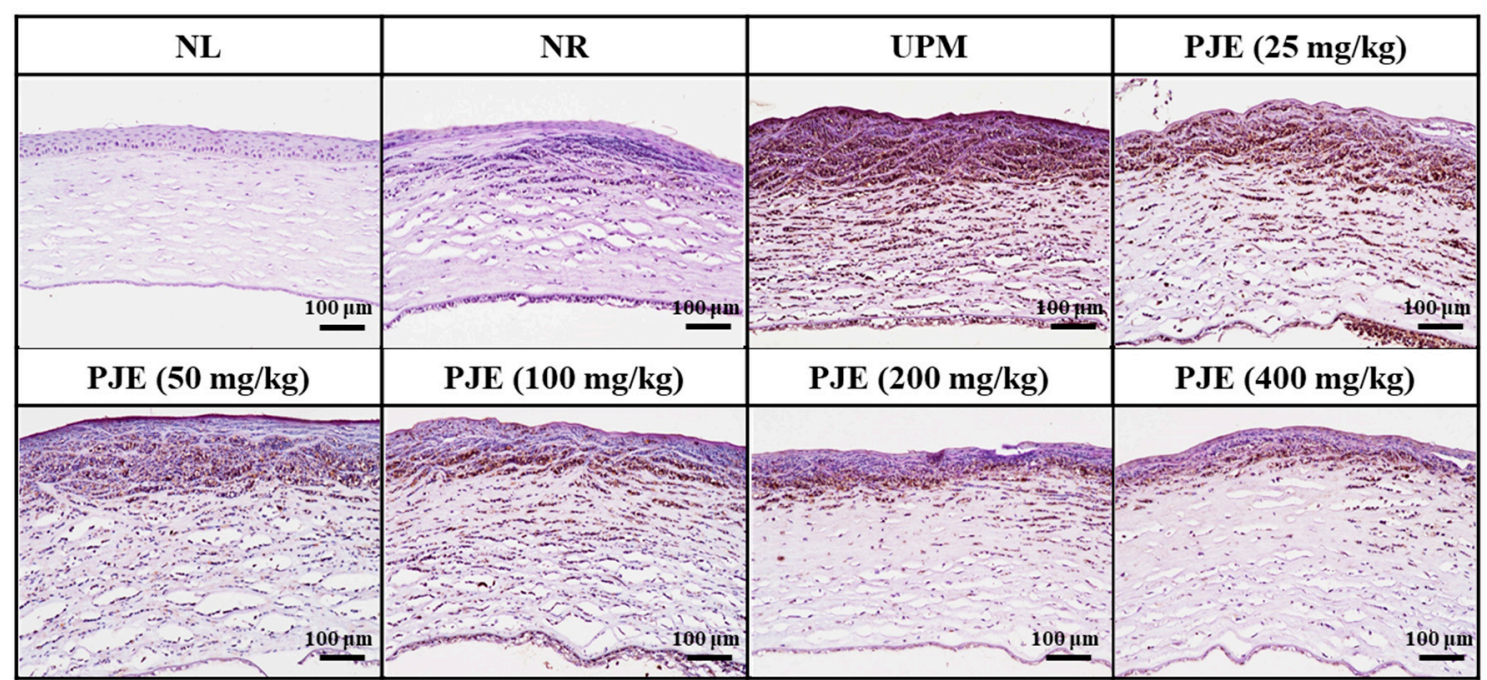

B

C
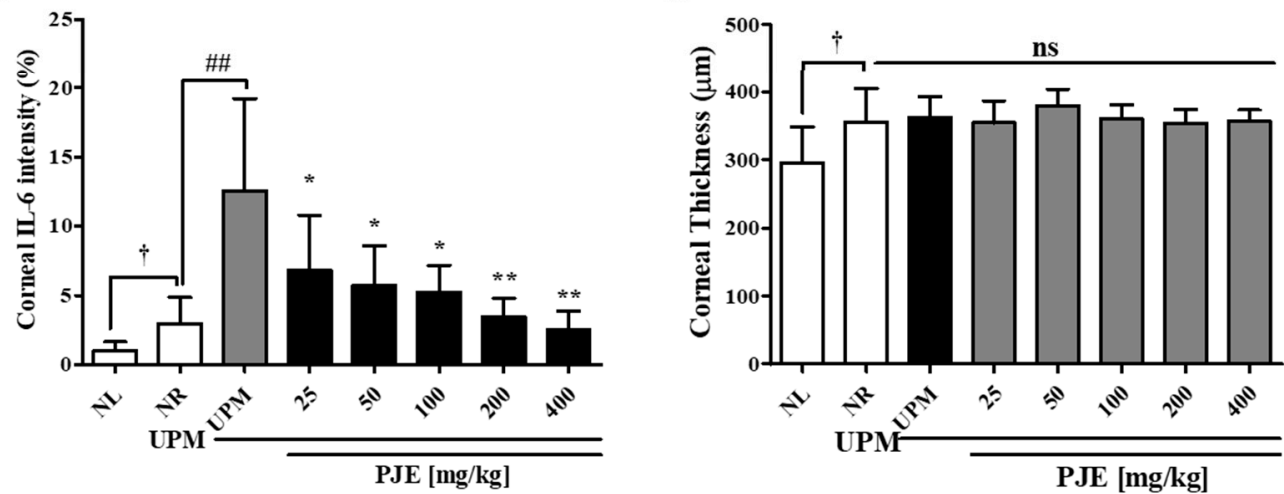

Figure 7. Immunohistological changes in IL-6 expression during corneal wound healing after treatment with PJE and after UPM exposure. (A) Immunohistochemical staining images for IL-6 in the corneas after $72 \mathrm{~h}$ were acquired at $200 \times$ magnification, and representative images are shown. (B) The intensities of the stained areas were calculated and the data are presented as the means $\pm \mathrm{SD}$. (C) The corneal thicknesses were calculated and are presented as the means \pm SD. ${ }^{\dagger} p<0.05$ compared to NL; ${ }^{\# \#} p<0.01$ compared to NR; ${ }^{*} p<0.05,{ }^{* *} p<0.01$ compared to UPM; ns, not significant.

\subsection{PJE Inhibits Apoptosis during Corneal Wound Healing after UPM Exposure}

As shown in Figure 8A,B, the few apoptotic cells (2.3\%) found in the NR group greatly increased to $10.4 \%$ by UPM exposure, which was significantly decreased in all PJE treatment groups, reaching the level of the NR group. Apoptotic cells were mainly distributed in the superficial region of the stroma and showed a slightly different distribution than that of IL-6. 

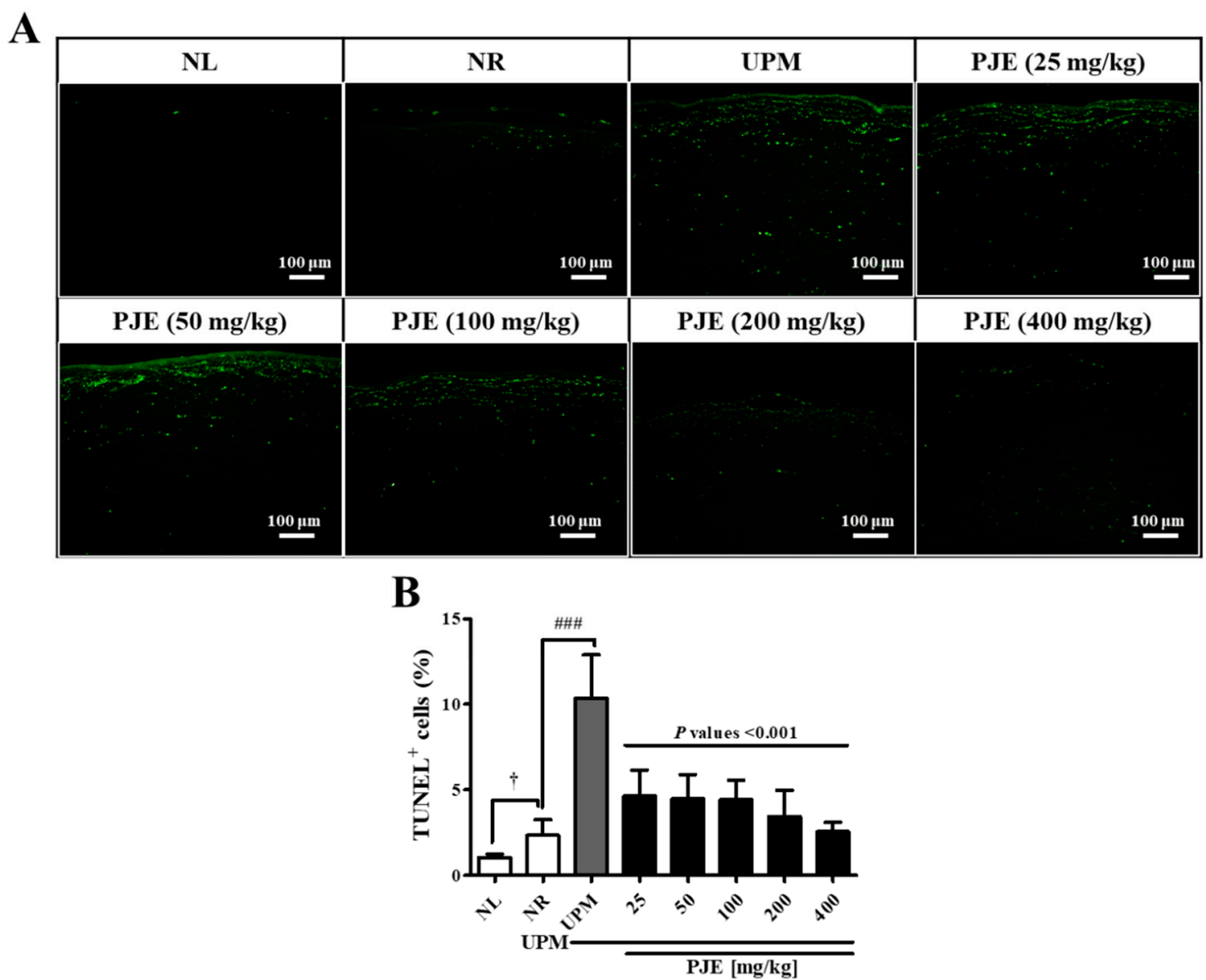

Figure 8. Apoptotic cells during corneal wound healing after treatment with PJE and after UPM exposure. (A) TUNEL staining images of the cornea at $72 \mathrm{~h}$ were acquired at $200 \times$ magnification, and representative images are shown. (B) The intensities of the apoptotic cells were calculated, and the results are presented as the means $\pm \mathrm{SD} .{ }^{+} p<0.05$ compared to NL; ${ }^{\# \# \# ~} p<0.001$ compared to NR. The $p$ values of all PJE groups were below 0.001 compared to UPM.

\subsection{Effects of PJE Solvent Fractionation on HCEC Wound Healing after UPM Exposure}

PJE was separated by solvent fractionation, and each fraction and assessed for its preventive effects on wound healing after UPM exposure. The HPLC chromatograms of each fraction are shown in Figure 9A, and the peaks of the major components (CAs) were mainly found in the $\mathrm{BuOH}$ fraction. The chloroform, ethyl acetate and water fractions showed CA peaks (approximately 16-20 $\mathrm{min}$ ), but many other peaks (approximately 36-52 $\mathrm{min}$ ) were also found in the chloroform and ethyl acetate fractions; notably, the water fraction clearly showed only CA peaks. Among the fractions, both the $\mathrm{BuOH}$ and water fractions enhanced the migration activity of the cells (Figure 9B) without altering their survival (Supplement Figure S1A-E). Both the $\mathrm{BuOH}$ and water fractions showed increasing migratory activity patterns at concentrations from $0.1 \mu \mathrm{g} / \mathrm{mL}$ to $3 \mu \mathrm{g} / \mathrm{mL}$, with a slight decrease at $30 \mu \mathrm{g} / \mathrm{mL}$ (Figure $9 \mathrm{C}, \mathrm{D}$ ). The pattern of these data presented a bell-shaped graph, which was the same as the data after PJE treatment, as shown in Figure 3B, although the water fraction showed a better effect than the $\mathrm{BuOH}$ fraction. To indirectly determine whether the residual peaks affected migration activity, mixtures of the $\mathrm{BuOH}$ and water fractions (1:2, 1:1 and 2:1) were assessed. The migration activities were enhanced by $20 \%$ after treatment with the 1:2 and 1:1 mixtures, and this activity was maintained at higher concentrations; additionally, the activity was slightly enhanced up to a concentration $3 \mu \mathrm{g} / \mathrm{mL}$ of the 2:1 mixture and then reduced at higher concentrations (Supplement Figure S2A-C). Therefore, the unknown components corresponding to the residual peaks 
in the PJE were predicted to inhibit the migratory activity at high concentrations, which was considered to be the cause of the bell-shaped curves.

A
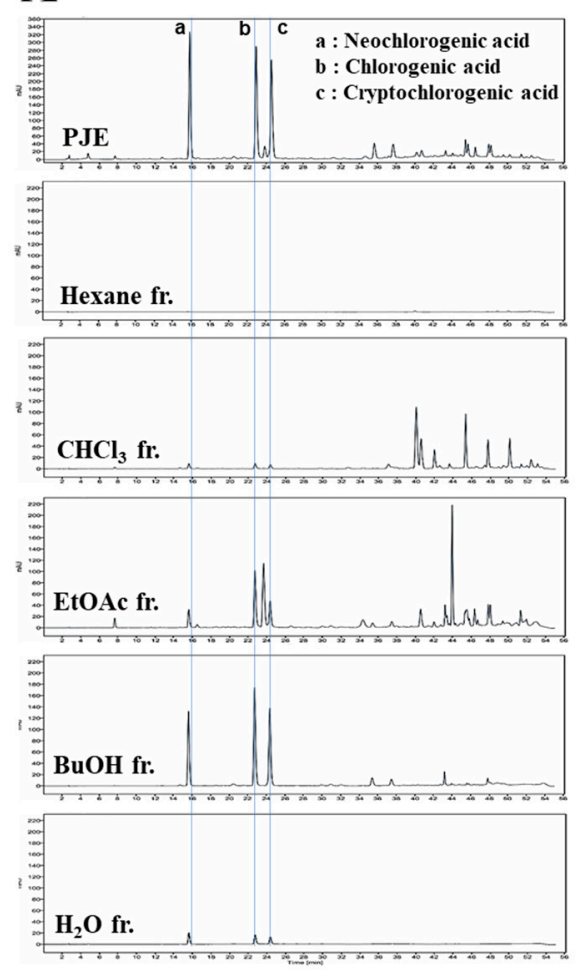

B

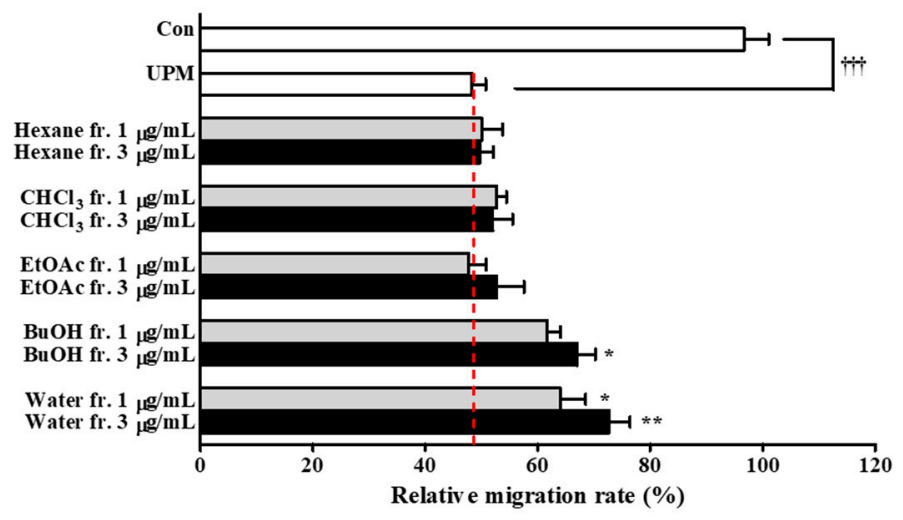

C

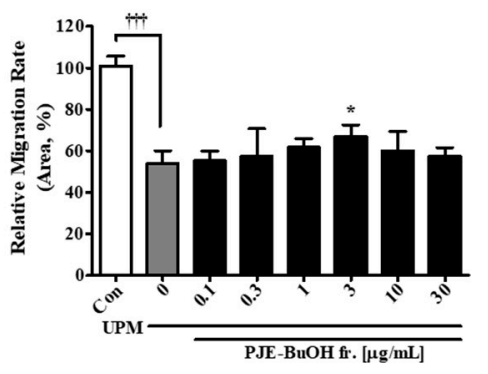

D

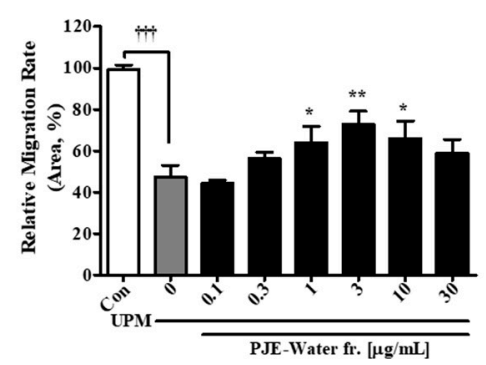

Figure 9. Fractions of PJE after solvent fractionations and their effects on HCEC wound healing. (A) HPLC chromatograms of the PJE and its fractions. (B) The migration rates of each fraction were calculated, and data from the concentrations of $1 \mu \mathrm{g} / \mathrm{mL}$ and $3 \mu \mathrm{g} / \mathrm{mL}$ are presented as the means $\pm \mathrm{SD}$. (C) The migration rates of the (C) $\mathrm{BuOH}$ fraction and (D) water fraction are presented as the means $\pm \mathrm{SD} .{ }^{++\dagger} p<0.001$ compared to Con; ${ }^{*} p<0.05,{ }^{* *} p<0.01$ compared to $0 \mu \mathrm{g} / \mathrm{mL}$ PJE.

\subsection{Open Column Chromatography of the PJE Water Fractions and Their Effect on the Wound} Healing of HCECs after UPM Exposure

The water PJE fraction was separated with an HP-20 column to purify the effective components and confirm its preventive effects. The HPLC chromatograms of each fraction (F0 F5) are shown in Figure 10A. The peaks from the CAs were mainly found in F1 F2, and some residual peaks appeared in F3 F5. The migratory activities of each fraction (F0 F5) were assessed with a scratch wound healing assay, and the activity after treatment with both F1 and F2 was significantly enhanced, whereas F3 F5 at the same concentrations only slightly inhibited migration (Figure 10B). None of the fractions changed the survival rate of the cells (Supplement Figure S3A-F). F1 showed better migration activity than F2 as expected due to the greater intensity of the HPLC peaks in F1. The migration activity after F1 treatment gradually increased by $22.3 \%$ with an increase in the concentration from $0 \mu \mathrm{g} / \mathrm{mL}$ to $1 \mu \mathrm{g} / \mathrm{mL}$, and this level was maintained at higher concentrations (Figure 10C). However, treatment with F5 led to a serial decrease in activity (Figure 10D). 
A

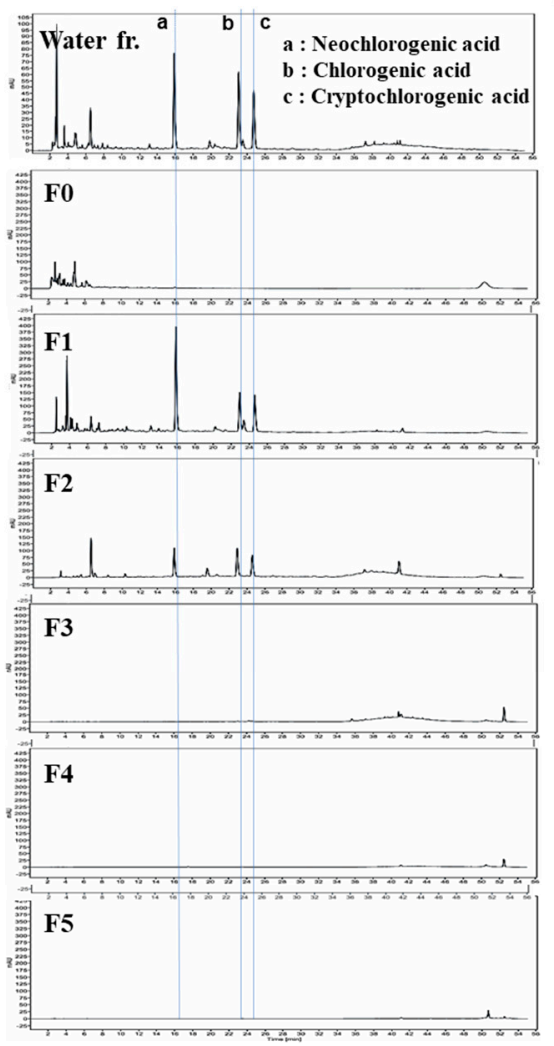

B

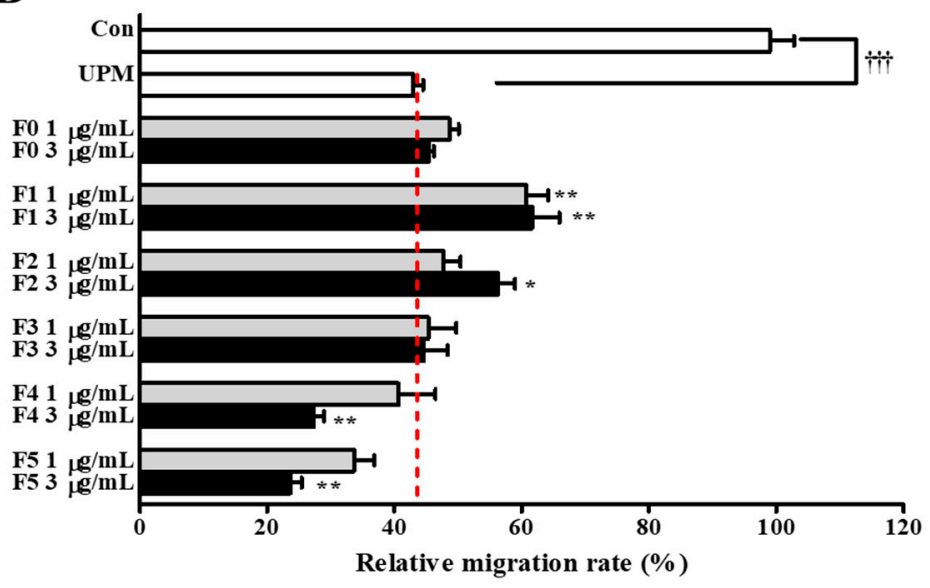

C

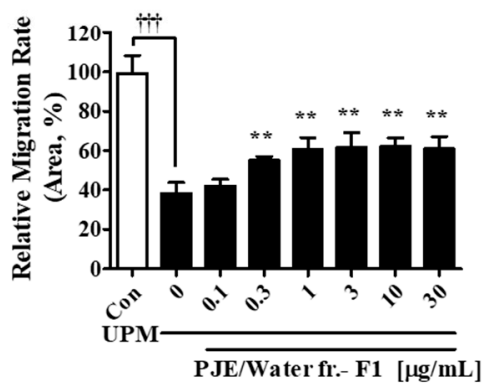

D

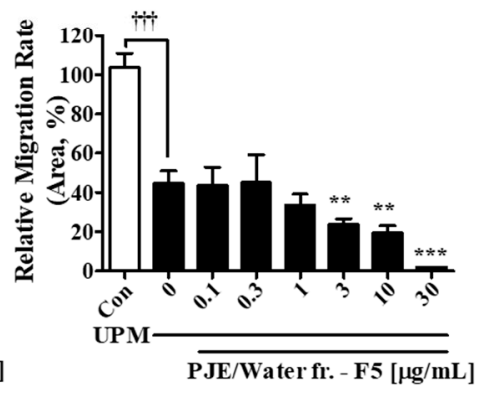

Figure 10. HP-20 open column chromatography of the water fraction of PJE (PJE/W) and the effects of these fractions on HCEC wound healing. (A) HPLC chromatograms of PJE and its fractions (F0 F5). (B) The migration rates of each fraction were calculated, and data from the concentrations of $1 \mu \mathrm{g} / \mathrm{mL}$ and $3 \mu \mathrm{g} / \mathrm{mL}$ are presented as the means $\pm \mathrm{SD}$. (C) The migration rates of (C) F1 and (D) F5 are presented as the means \pm SD. ${ }^{++\dagger} p<0.001$ compared to Con; ${ }^{*} p<0.05,{ }^{* *} p<0.01$ *** $p<0.001$ compared to $0 \mu \mathrm{g} / \mathrm{mL}$ PJE.

3.10. The Preventive Effects of PJE on the Wound Healing of HCECs after UPM Exposure Were Dependent on the Three Major Compounds CA, NCA and CCA

Finally, the results of this study suggested that the preventive effects of PJE on HCEC wound healing after UPM exposure were dependent on the three major compounds CA, NCA and CCA. To confirm the effectiveness of each compound, each CA individually, each mixture of two CAs and a mixture of all three CAs were assessed for their migration activity (Figure 11A). Their concentration ranges were determined similarly to the abovetested PJE levels. All tested CA materials showed significantly increased activity, and mixtures of two or three had better responses than the single agents. None of the CAs changed cell survival (Supplement Figure S4A-C). Their $\mathrm{EC}_{50}$ and $\mathrm{EC}_{\max }$ values are shown in Table 2. The $\mathrm{EC}_{50}$ were NCA $(0.203 \pm 0.040 \mu \mathrm{M}), \mathrm{CCA}(0.235 \pm 0.069 \mu \mathrm{M})$ and CA $(0.458 \pm 0.170 \mu \mathrm{M})$, whereas the $\mathrm{EC}_{\max }$ values were NCA $(51.0 \%), \mathrm{CCA}(54.7 \%)$ and CA $(56.0 \%)$ (Figure 11B). These results indicate that the response occurred at low concentrations in the order of NCA, CCA and CA but showed the highest effect in the order of CA, CCA and NCA without significance. The $\mathrm{EC}_{\max }$ values also showed a similar pattern to the $\mathrm{EC}_{50}$ values. The features of each $\mathrm{CA}$ were also displayed as a result of the $\mathrm{EC}_{50}$ values of each mixture of two CAs. The $\mathrm{EC}_{50}$ values of each mixture were CCA + NCA $(0.209 \pm 0.044 \mu \mathrm{M})$, $\mathrm{CA}+\mathrm{NCA}(0.210 \pm 0.025 \mu \mathrm{M})$ and $\mathrm{CA}+\mathrm{CCA}(0.630 \pm 0.062 \mu \mathrm{M})$, whereas the $\mathrm{EC}_{\max }$ values were CCA + NCA (60.3\%), CA + NCA (63.0\%) and CA + CCA (68.7\%) (Figure 11C). The mixture of three CAs showed the lowest $\mathrm{EC}_{50}(0.150 \pm 0.020 \mu \mathrm{M})$ and the highest $\mathrm{EC}_{\max }$ value (81.7\%) (Figure 11D). Interestingly, a bell-shaped curve did not appear after 
CA treatment. These results could be the reason why the animal experiment showed better than expected results because the CAs synergistically enhanced the preventive effects.

A
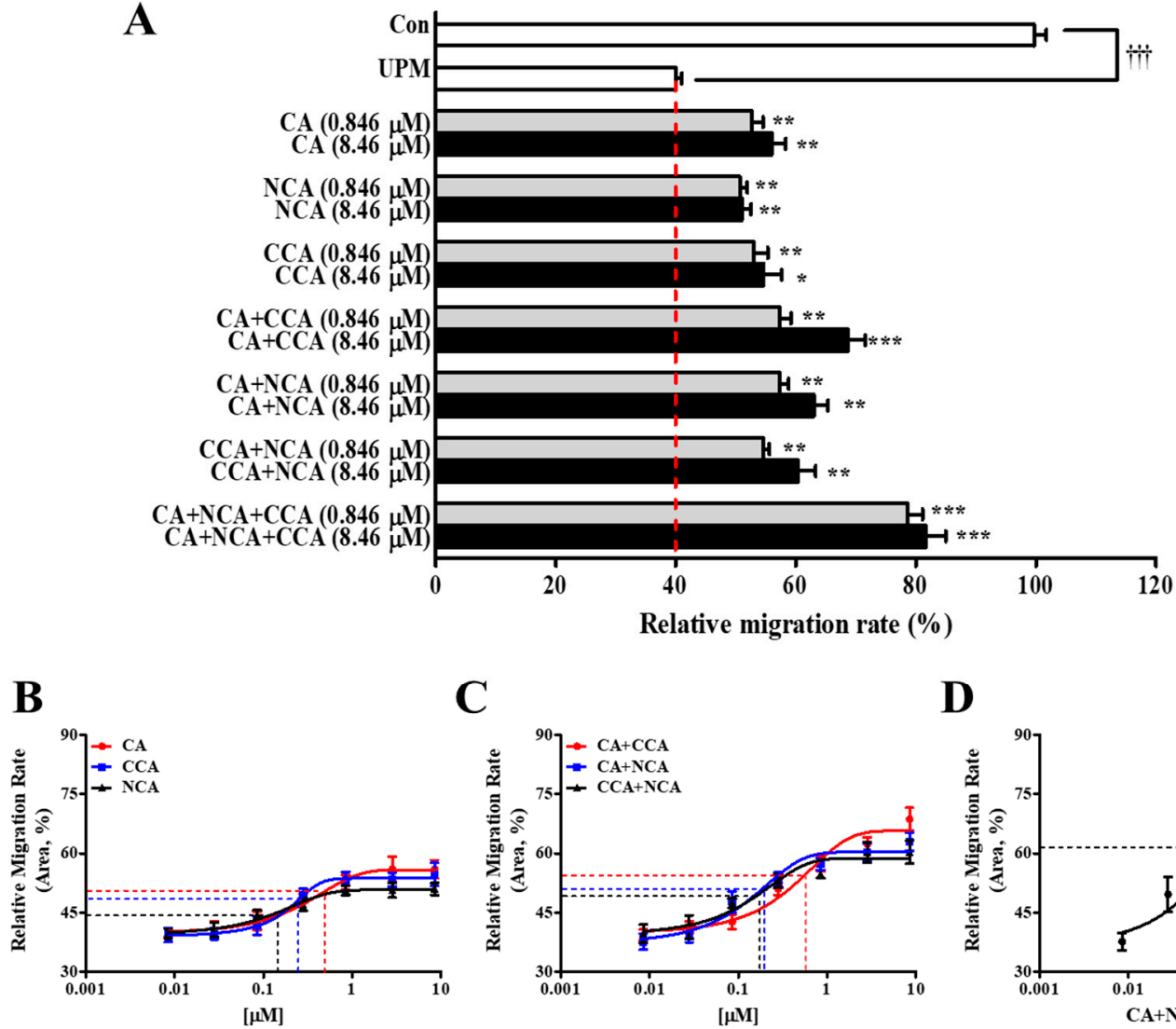

C

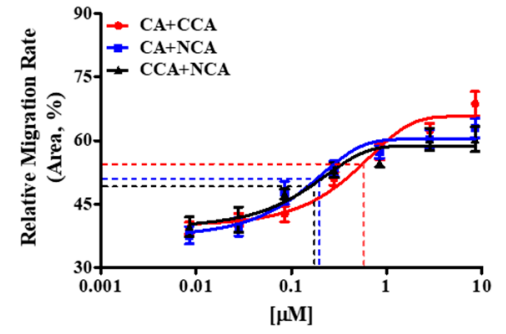

D

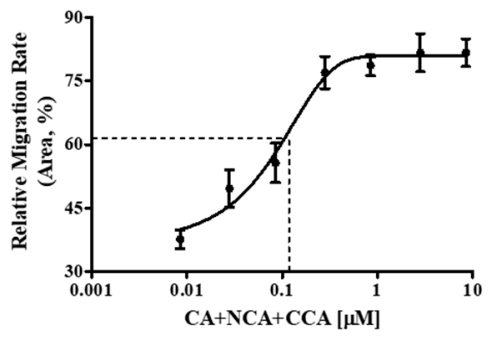

Figure 11. Effects of the major components of PJE on wound healing. (A) The migration rates of each CA and their mixtures were calculated, and data from the concentrations of $0.846 \mu \mathrm{M}$ and $8.46 \mu \mathrm{M}$ are presented as the means $\pm \mathrm{SD}$. The relative migration rates of $(\mathbf{B})$ each CA individually, $(\mathbf{C})$ double CA mixtures and $(\mathbf{D})$ the triple CA mixture are presented as the means $\pm \mathrm{SD}$; their $\mathrm{EC}_{50}$ values are indicated by dotted lines. ${ }^{++\dagger} p<0.001$ compared to Con; ${ }^{*} p<0.05,{ }^{* *} p<0.01{ }^{* * *} p<0.001$ compared to $0 \mu \mathrm{g} / \mathrm{mL}$ PJE.

Table 2. The $\mathrm{EC}_{50}$ and $\mathrm{EC}_{\max }$ values of each $\mathrm{CA}$ and their mixtures on wound healing.

\begin{tabular}{|c|c|c|}
\hline & $\mathrm{EC}_{50}$ & $\mathrm{EC}_{\max }$ \\
\hline & \multicolumn{2}{|c|}{$[\mu \mathrm{M}]$} \\
\hline CA & $0.458 \pm 0.170$ & $2.637 \pm 0.615$ \\
\hline CCA & $0.235 \pm 0.069 \#$ & $0.897 \pm 0.232 * * *$,\#\#\# \\
\hline NCA & $0.203 \pm 0.040^{\# \#}$ & 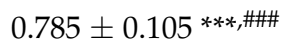 \\
\hline $\mathrm{CA}+\mathrm{CCA}$ & $0.630 \pm 0.062$ & $3.103 \pm 0.337$ \\
\hline $\mathrm{CA}+\mathrm{NCA}$ & $0.210 \pm 0.025^{\# \#}$ & 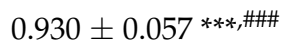 \\
\hline $\mathrm{CCA}+\mathrm{NCA}$ & $0.209 \pm 0.044$ \#\# & 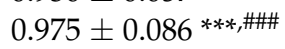 \\
\hline $\mathrm{CA}+\mathrm{CCA}+\mathrm{NCA}$ & $0.150 \pm 0.020 * \# \# \#$ & 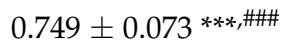 \\
\hline
\end{tabular}

The values are presented as the means \pm SD. ${ }^{\# \#} p<0.01,{ }^{\# \# \#} p<0.001$ compared to CA + CCA; ${ }^{*} p<0.05$, *** $p<0.001$ compared to CA.

\section{Discussion}

A shallow scratch on the ocular surface quickly heals through the migration and proliferation of corneal epithelial cells. However, normal wound healing can be disturbed by a deep mechanical scratch or by interrupting factors such as metabolic disorders, an allergic response, inflammation or dry eye, which can lead to adverse effects, including amblyopia, cloudiness, irritation and permanent opacification [44-46]. Recently, UPM 
has been found to be a cause of various ocular diseases, including dry eye-like disease, allergic conjunctivitis and presbyopia, because its presence has increased due to industrial development and its easy daily exposure to the eye [13-15]. The harmful effects of UPM on the eye have also been substantially investigated, and its cytotoxicity, immunogenicity and oxidative stimulation have been revealed; consequentially, delayed corneal wound healing after UPM exposure has also been reported in animal studies [5-8,24]. However, these data are insufficient to comprehensively understand the effects of UPM on corneal wound healing, even though the mechanisms have been suggested by various in vitro studies. Therefore, the ocular changes that occur after UPM exposure during wound healing and a screening for a preventive agent from an herbal extract were investigated in this study.

The screening of effective materials was accomplished by performing a scratch wound healing assay in HCECs after exposure to UPM, and a PJE that showed a significant effect on healing was selected as a candidate. HCEC survival was unchanged by PJE, which means that PJE enhanced the migration activity of these cells (Figure 3). It should be noted that the cells were tested without serum supplementation, which is necessary for cell proliferation, so the changes in migration activity caused by PJE were clearer.

Oxidative stress has been reported to be a major cause of epithelial dysfunction $[7,8,47]$, and the mRNA expression levels of the key antioxidative genes SOD1, CAT, HO1 and GPX1 were quantitated by real-time PCR. CAT, HO1 and GPX1 were significantly upregulated by PJE treatment, and both HO1 and GPX1 were slightly upregulated by UPM, but SOD1 expression did not change (Figure 4). The slight increases shown after UPM treatment were thought to be due to the activation of the host defense because a similar pattern had been reported previously [48]. Enhanced antioxidative gene expression by PJE is expected to be a preventive mechanism of delayed wound healing after UPM exposure.

For animal studies, it is necessary to evaluate the effectiveness of prophylactic agents by treating the appropriate concentrations of UPM. A similar study demonstrated that PM at $5 \mathrm{mg} / \mathrm{mL}$ is suitable for analyzing molecular changes during injury $[5,17]$. Our previous study also showed a time-dependent change by UPM at the $5 \mathrm{mg} / \mathrm{mL}$ concentration [12]. Therefore, $5 \mathrm{mg} / \mathrm{mL}$ of UPM was applied in animal experiments. PJE was used as an oral pretreatment to rats with UPM exposure before wound generation to examine the preventive effects of PJE on corneal recovery. The restoration of larger wounds occurred in a time-dependent manner and was almost complete after $72 \mathrm{~h}$, and all PJE-treated groups showed a better recovery rate than the UPM-only exposed group (Figure 5). Surprisingly, tissue analysis showed that the increased immune cell infiltration by UPM exposure was reduced by PJE, and re-epithelialization was enhanced (Figure 6). Expression of the inflammatory factor IL-6 (Figure 7) and the apoptotic cell number (Figure 8) were also decreased by PJE treatment. Normally, apoptotic cells in the corneal epithelium are involved in tissue homeostasis, and their presence can be slightly increased during wound healing to remove inflammatory cells $[49,50]$. In normal wound healing, a few infiltrating immune cells, such as neutrophils and macrophages, are needed to prevent infection from microbes and to enhance the recovery process by regulating marginal cells. Neutrophils have been reported to be necessary for re-epithelialization after abrasion $[51,52]$ and to affect the recovery of the corneal nerves by vascular endothelial growth factor-A (VEGF-A) secretion [53]. Macrophages also help wound recovery by removing debris and apoptotic cells from the wound site and secreting various growth factors to induce the proliferation of epithelial cells or the differentiation of fibroblasts to myofibroblasts $[49,50]$. However, UPM exposure increased immune cell infiltration, and excessive inflammation was induced, as shown by the increases in IL-6 expression and apoptosis. In addition, debris clearance was delayed, as shown by the accumulation of apoptotic cells in the superficial site of the wounded cornea, whereas inflammation was still activated, as shown by the distribution of IL-6 expression in the subsuperficial site, which probably disturbed the normal recovery process.

PJE has been reported to contain numerous compounds, as described above, and three CAs showed powerful antioxidative activity [41]. Some studies also reported the anti- 
oxidative function of PJE by direct assay such as DPPH assay to test free radical scavenging activity. Therefore, the anti-oxidative function of PJE is one of the key properties for a delayed wound healing improvement via direct and indirect mechanisms [54,55]. Based on these data, the PJE was separated by solvent fractionation, and the effects of the fractions on the migration activity were assessed to confirm the effective molecules and their isolation conditions. None of the fractions affected cell survival, but the migration activity was improved by the $\mathrm{BuOH}$ and water fractions (Figure 9). However, unexpectedly, the effects of the water fraction were better than those of the $\mathrm{BuOH}$ fraction, although the peak sizes of the $\mathrm{CAs}$ in the $\mathrm{BuOH}$ fraction were larger. Experiments using mixtures of the $\mathrm{BuOH}$ and water fractions at various ratios were performed to determine whether the non-CA peaks may indirectly function as inhibitors of migration. It was found that as the ratio of the $\mathrm{BuOH}$ fraction increased, a reduced effect on migration activity was produced; therefore, the effects of these residual peaks were considered in the following experiments.

The water fraction showed the best effect on cell migration, but these effects were reduced at higher concentrations because small amounts of the compounds that formed the residual peaks were probably still included. Therefore, the water fraction was separated by HP-20 open column chromatography, and each fraction was assessed for its effect on migration (Figure 10). The CA peaks appeared in F1, which efficiently improved migration activity that did not decline after treatment with higher concentrations, whereas increasing concentrations of F3 F5 led to serial decreases in activity. These results indicate that some unknown inhibitory compounds are included in the PJE and that the CAs were confirmed to be the effective compounds. Finally, the effects on the migration of each CA alone or mixtures of two or three CAs were assessed to determine if each CA acted differently or whether mixtures could enhance the effects synergistically. Each CA showed slightly different $\mathrm{EC}_{50}$ and $\mathrm{EC}_{\max }$ values, and the mixture of all three showed the best effect on migration. Based on these results, a mixture of all three CAs would be more effective for corneal wound healing, and the inhibitory effects of the unknown components of the PJE found through the in vitro experiments probably disappeared during metabolism. Studies in various fields have focused on CA, which is abundant in foods (especially coffee), for a long time. Many beneficial properties of CA have been reported, such as its abilities to lower the risk of metabolic syndromes and chronic diseases [56]. In addition to the beneficial effects of CA on metabolic syndromes [57], CA is also active against hepatic steatosis [58], neurodegenerative diseases [59], cardiovascular diseases [60] and cancer [61]. The antioxidative function of CA is a representative property, and it promotes diabetic wound recovery [62]. The detailed mechanisms of CA on corneal wound healing after UPM exposure will be further studied considering the relationships between each type of cell.

Herein, the preventive effects of PJE on corneal wound healing after UPM exposure were well studied through its antioxidative and anti-inflammatory properties, and the effective components were clearly defined. However, limitations of this study also exist; for example, UPM exposure from an eye drop solution is not realistic, although most similar studies have used this method; the residual peaks that inhibited migration were not identified; and the infiltrating cell types and how they interacted with other cells were not defined. Therefore, although the detailed mechanisms of CAs as preventive agents for corneal wound healing after UPM exposure focused on epithelial cells, fibroblasts and keratocyte inflammatory cells and their relationship, the molecular mechanisms should be further studied.

\section{Conclusions}

In the present study, UPM influenced corneal wound healing by causing inflammation, oxidative stress and apoptosis. PJE was selected through a screening of herbal extracts to promote the recovery rate of wounded corneas and was found to efficiently improve the wound healing and migration activity of corneal epithelial cells. The major components were defined as CA, NCA and CCA, which were effective individually on the migration 
activity, and they synergistically enhanced this effect. These data provide valuable information for the application of PJE to treat corneal injury accompanied by inflammation and oxidative stress.

Supplementary Materials: The following are available online at https:/ /www.mdpi.com/article/10 .3390/antiox10111717/s1, Figure S1: Effects of PJE solvent fractionation on HCEC survival, Figure S2: Effects of PJE fraction mixtures (BuOH and water fractions) on HCEC wound healing, Figure S3: Effects of the PJE/Water fractions after HP-20 open column chromatography on the survival of HCECs, Figure S4: Effects of the CA isomers on the survival of HCECs.

Author Contributions: Conceptualization, S.K.; data curation, W.S.K.; formal analysis, K.J.K. and H.C.; funding acquisition, S.K. and C.-S.N.; methodology, K.H.L. and E.K.; project administration, S.K.; resources, J.S.K. and C.-S.N.; writing—original draft, S.K.; and writing—review and editing, C.-S.N. and S.K. All authors have read and agreed to the published version of the manuscript.

Funding: This research was supported by a Korea Innovation Foundation (INNIPOLIS) grant funded by the Korean government (Ministry of Science and ICT) through a Science and Technology Project that opens the future of the region (grant number: 2021-DD-UP-0380). The funding body did not play a role in the study design, performance, data collection and analysis, decision to publish or preparation/writing of the manuscript.

Institutional Review Board Statement: This study was conducted according to animal ethics guidelines and was approved by the institutional animal care and use committee (IACUC) of Bioresources and Technology (B\&Tech) Co., Ltd., Republic of Korea (approval number: BT-003-2020, July 2020).

Informed Consent Statement: Not applicable.

Data Availability Statement: The data presented in this study are available in article and supplementary material.

Acknowledgments: We sincerely appreciate the other colleagues in our laboratory for their help and effort in this study.

Conflicts of Interest: The authors declare no conflict of interest.

\section{References}

1. Valko, M.; Leibfritz, D.; Moncol, J.; Cronin, M.T.; Mazur, M.; Telser, J. Free radicals and antioxidants in normal physiological functions and human disease. Int. J. Biochem. Cell Biol. 2007, 39, 44-84. [CrossRef]

2. Guo, Y.; Jia, Y.; Pan, X.; Liu, L.; Wichmann, H.-E. The association between fine particulate air pollution and hospital emergency room visits for cardiovascular diseases in Beijing, China. Sci. Total Environ. 2009, 407, 4826-4830. [CrossRef] [PubMed]

3. Camara, J.G.; Lagunzad, J.K.D. Ocular findings in volcanic fog induced conjunctivitis. Hawaii Med. J. 2011, 70, 262. [PubMed]

4. Tecer, L.H.; Alagha, O.; Karaca, F.; Tuncel, G.; Eldes, N. Particulate matter (PM2.5, PM10-2.5, and PM10) and children's hospital admissions for asthma and respiratory diseases: A bidirectional case-crossover study. J. Toxicol. Environ. Health Part A 2008, 71, 512-520. [CrossRef] [PubMed]

5. Shao, Y. Air pollutant particulate matter 2.5 induces dry eye syndrome in mice. Investig. Ophthalmol. Vis. Sci. 2018, 59, 3839.

6. Fu, Q.; Lyu, D.; Zhang, L.; Qin, Z.; Tang, Q.; Yin, H.; Lou, X.; Chen, Z.; Yao, K. Airborne particulate matter (PM2.5) triggers autophagy in human corneal epithelial cell line. Environ. Pollut. 2017, 227, 314-322. [CrossRef]

7. Hyun, S.-W.; Song, S.J.; Park, B.; Lee, T.G.; Kim, C.-S. Toxicological effects of urban particulate matter on corneal and conjunctival epithelial cells. Toxicol. Res. 2020, 1-8. [CrossRef]

8. Lyu, D.; Almansoob, S.; Chen, H.; Ye, Y.; Song, F.; Zhang, L.; Qin, Z.; Tang, Q.; Yin, H.; Xu, W. Transcriptomic profiling of human corneal epithelial cells exposed to airborne fine particulate matter (PM2.5). Ocul. Surf. 2020, 18, 554-564. [CrossRef]

9. Yoon, S.; Han, S.; Jeon, K.-J.; Kwon, S. Effects of collected road dusts on cell viability, inflammatory response, and oxidative stress in cultured human corneal epithelial cells. Toxicol. Lett. 2018, 284, 152-160. [CrossRef]

10. Li, J.; Tan, G.; Ding, X.; Wang, Y.; Wu, A.; Yang, Q.; Ye, L.; Shao, Y. A mouse dry eye model induced by topical administration of the air pollutant particulate matter 10. Biomed. Pharmacother. 2017, 96, 524-534. [CrossRef] [PubMed]

11. Niederkorn, Y.; Cornea, J. Window to ocular immunology. Curr. Immunol. Rev. 2011, 7, 328-335. [CrossRef]

12. Kang, W.S.; Choi, H.; Jang, G.; Lee, K.H.; Kim, E.; Kim, K.J.; Jeong, G.-Y.; Kim, J.S.; Na, C.-S.; Kim, S. Long-term exposure to urban particulate matter on the ocular surface and the incidence of deleterious changes in the cornea, conjunctiva and retina in rats. Int. J. Mol. Sci. 2020, 21, 4976. [CrossRef]

13. Moen, B.E.; Norbäck, D.; Wieslander, G.; Bakke, J.V.; Magerøy, N.; Granslo, J.T.; Irgens, Å.; Bråtveit, M.; Hollund, B.E.; Aasen, T. Can air pollution affect tear film stability? A cross-sectional study in the aftermath of an explosion accident. BMC Public Health 2011, 11, 1-6. [CrossRef] 
14. Mimura, T.; Ichinose, T.; Yamagami, S.; Fujishima, H.; Kamei, Y.; Goto, M.; Takada, S.; Matsubara, M. Airborne particulate matter (PM2.5) and the prevalence of allergic conjunctivitis in Japan. Sci. Total Environ. 2014, 487, 493-499. [CrossRef]

15. Lin, H.; Guo, Y.; Ruan, Z.; Yang, Y.; Chen, Y.; Zheng, Y.; Cummings-Vaughn, L.A.; Rigdon, S.E.; Vaughn, M.G.; Sun, S. Ambient PM2.5 and $\mathrm{O}_{3}$ and their combined effects on prevalence of presbyopia among the elderly: A cross-sectional study in six low-and middle-income countries. Sci. Total Environ. 2019, 655, 168-173. [CrossRef]

16. Jung, S.J.; Mehta, J.S.; Tong, L. Effects of environment pollution on the ocular surface. Ocul. Surf. 2018, 16, 198-205. [CrossRef] [PubMed]

17. Yang, Q.; Li, K.; Li, D.; Zhang, Y.; Liu, X.; Wu, K. Effects of fine particulate matter on the ocular surface: An in vitro and in vivo study. Biomed. Pharmacother. 2019, 117, 109177. [CrossRef] [PubMed]

18. Yang, Q.; Tang, L.; Shen, M.; Wang, Y.; Wei, Y.; Jeyalatha, V.; Chen, P.; Dong, F.; Wang, G.; Wu, S. Effects of diesel exhaust particles on the condition of mouse ocular surface. Ecotoxicol. Environ. Saf. 2018, 163, 585-593. [CrossRef] [PubMed]

19. Channa, R.; Zafar, S.N.; Canner, J.K.; Haring, R.S.; Schneider, E.B.; Friedman, D.S. Epidemiology of eye-related emergency department visits. JAMA Ophthalmol. 2016, 134, 312-319. [CrossRef] [PubMed]

20. May, D.R.; R, D.; Kuhn, F.P.; Morris, R.E.; Witherspoon, C.D.; Danis, R.; Matthews, G.; Mann, L. The epidemiology of serious eye injuries from the United States Eye Injury Registry. Graefe's Arch. Clin. Exp. Ophthalmol. 2000, 238, 153-157. [CrossRef] [PubMed]

21. Gekka, M.; Miyata, K.; Nagai, Y.; Nemoto, S.; Sameshima, T.; Tanabe, T.; Maruoka, S.; Nakahara, M.; Kato, S.; Amano, S. Corneal epithelial barrier function in diabetic patients. Cornea 2004, 23, 35-37. [CrossRef]

22. Danjo, Y.; Gipson, I.K. Specific transduction of the leading edge cells of migrating epithelia demonstrates that they are replaced during healing. Exp. Eye Res. 2002, 74, 199-204. [CrossRef] [PubMed]

23. Danjo, Y.; Gipson, I.K. Actin 'purse string'filaments are anchored by E-cadherin-mediated adherens junctions at the leading edge of the epithelial wound, providing coordinated cell movement. J. Cell Sci. 1998, 111, 3323-3332. [CrossRef] [PubMed]

24. Cui, Y.-H.; Hu, Z.-X.; Gao, Z.-X.; Song, X.-L.; Feng, Q.-Y.; Yang, G.; Li, Z.-J.; Pan, H.-W. Airborne particulate matter impairs corneal epithelial cells migration via disturbing FAK/RhoA signaling pathway and cytoskeleton organization. Nanotoxicology 2018, 12, 312-324. [CrossRef]

25. Nagata, M.; Nakamura, T.; Hata, Y.; Yamaguchi, S.; Kaku, T.; Kinoshita, S. JBP485 promotes corneal epithelial wound healing. Sci. Rep. 2015, 5, 1-8. [CrossRef] [PubMed]

26. Zhang, Y.; Chen, P.; Di, G.; Qi, X.; Zhou, Q.; Gao, H. Netrin-1 promotes diabetic corneal wound healing through molecular mechanisms mediated via the adenosine $2 \mathrm{~B}$ receptor. Sci. Rep. 2018, 8, 1-12. [CrossRef]

27. Tong, L.; Png, E.; AiHua, H.; Yong, S.S.; Yeo, H.L.; Riau, A.; Mendoz, E.; Chaurasia, S.S.; Lim, C.T.; Yiu, T.W. Molecular mechanism of transglutaminase-2 in corneal epithelial migration and adhesion. Biochim. Biophys. Acta (BBA)-Mol. Cell Res. 2013, 1833, 1304-1315. [CrossRef]

28. Yamada, N.; Yanai, R.; Kawamoto, K.; Nagano, T.; Nakamura, M.; Inui, M.; Nishida, T. Promotion of corneal epithelial wound healing by a tetrapeptide (SSSR) derived from IGF-1. Investig. Ophthalmol. Vis. Sci. 2006, 47, 3286-3292. [CrossRef]

29. Maulvi, F.A.; Soni, T.G.; Shah, D.O. Extended release of hyaluronic acid from hydrogel contact lenses for dry eye syndrome. $J$. Biomater. Sci. Polym. Ed. 2015, 26, 1035-1050. [CrossRef]

30. Urtti, A. Challenges and obstacles of ocular pharmacokinetics and drug delivery. Adv. Drug Deliv. Rev. 2006, 58, 1131-1135. [CrossRef]

31. World Health Organization. Medicinal Plants in the Republic of Korea: Information on 150 commonly Used Medicinal Plants; WHO Regional Office for the Western Pacific: Manila, Philippines, 1998.

32. Kim, S.H.; Jong, H.S.; Yoon, M.H.; Oh, S.H.; Jung, K.T. Antinociceptive effect of intrathecal sec-O-glucosylhamaudol on the formalin-induced pain in rats. Korean J. Pain 2017, 30, 98. [CrossRef] [PubMed]

33. Hong, M.J.; Kim, J. Determination of the absolute configuration of khellactone esters from Peucedanum japonicum Roots. J. Nat. Prod. 2017, 80, 1354-1360. [CrossRef]

34. Hisamoto, M.; Kikuzaki, H.; Nakatani, N. Constituents of the leaves of Peucedanum japonicum Thunb. and their biological activity. J. Agric. Food Chem. 2004, 52, 445-450. [CrossRef]

35. Nugara, R.N.; Inafuku, M.; Takara, K.; Iwasaki, H.; Oku, H. Pteryxin: A coumarin in Peucedanum japonicum Thunb leaves exerts antiobesity activity through modulation of adipogenic gene network. Nutrition 2014, 30, 1177-1184. [CrossRef]

36. Taira, N.; Nugara, R.N.; Inafuku, M.; Takara, K.; Ogi, T.; Ichiba, T.; Iwasaki, H.; Okabe, T.; Oku, H. In vivo and in vitro anti-obesity activities of dihydropyranocoumarins derivatives from Peucedanum japonicum Thunb. J. Funct. Foods 2017, 29, 19-28. [CrossRef]

37. Chen, I.-S.; Chang, C.-T.; Sheen, W.-S.; Teng, C.-M.; Tsai, I.-L.; Duh, C.-Y.; Ko, F.-N. Coumarins and antiplatelet aggregation constituents from Formosan Peucedanum japonicum. Phytochemistry 1996, 41, 525-530. [CrossRef]

38. Hsiao, G.; Ko, F.-N.; Jong, T.-T.; Teng, C.-M. Antiplatelet action of 3', 4'-diisovalerylkhellactone diester purified from Peucedanum japonicum Thunb. Biol. Pharm. Bull. 1998, 21, 688-692. [CrossRef] [PubMed]

39. Takeuti, N.; Kasama, T.; Aida, Y.; Oki, J.; Maruyama, I.; Watanabe, K.; Tobinaga, S. Pharmacological activities of the prenylcoumarins, developed from folk usage as a medicine of Peucedanum japonicum THUNB. Chem. Pharm. Bull. 1991, 39, 1415-1421. [CrossRef] [PubMed]

40. Chun, J.M.; Lee, A.R.; Kim, H.S.; Lee, A.Y.; Gu, G.J.; Moon, B.C.; Kwon, B.-I. Peucedanum japonicum extract attenuates allergic airway inflammation by inhibiting Th2 cell activation and production of pro-inflammatory mediators. J. Ethnopharmacol. 2018, 211, 78-88. [CrossRef] [PubMed] 
41. Hisamoto, M.; Kikuzaki, H.; Ohigashi, H.; Nakatani, N. Antioxidant compounds from the leaves of Peucedanum japonicum Thunb. J. Agric. Food Chem. 2003, 51, 5255-5261. [CrossRef] [PubMed]

42. Taira, J.; Ogi, T. Induction of antioxidant protein HO-1 through Nrf2-ARE signaling due to pteryxin in Peucedanum japonicum Thunb in RAW264.7 macrophage cells. Antioxidants 2019, 8, 621. [CrossRef] [PubMed]

43. Lu, H.; Tian, Z.; Cui, Y.; Liu, Z.; Ma, X. Chlorogenic acid: A comprehensive review of the dietary sources, processing effects, bioavailability, beneficial properties, mechanisms of action, and future directions. Compr. Rev. Food Sci. Food Saf. 2020, 19, 3130-3158. [CrossRef]

44. Aslam, S.; Sheth, H.; Vaughan, A. Emergency management of corneal injuries. Injury 2007, 38, 594-597. [CrossRef]

45. Bu, Y.; Shih, K.C.; Kwok, S.S.; Chan, Y.K.; Lo, A.C.-Y.; Chan, T.C.Y.; Jhanji, V.; Tong, L. Experimental modeling of cornea wound healing in diabetes: Clinical applications and beyond. BMJ Open Diabetes Res. Care 2019, 7, e000779. [CrossRef] [PubMed]

46. Bukowiecki, A.; Hos, D.; Cursiefen, C.; Eming, S.A. Wound-healing studies in cornea and skin: Parallels, differences and opportunities. Int. J. Mol. Sci. 2017, 18, 1257. [CrossRef] [PubMed]

47. Zheng, Q.; Ren, Y.; Reinach, P.S.; She, Y.; Xiao, B.; Hua, S.; Qu, J.; Chen, W. Reactive oxygen species activated NLRP3 inflammasomes prime environment-induced murine dry eye. Exp. Eye Res. 2014, 125, 1-8. [CrossRef]

48. Xiang, P.; He, R.-W.; Han, Y.-H.; Sun, H.-J.; Cui, X.-Y.; Ma, L.-Q. Mechanisms of housedust-induced toxicity in primary human corneal epithelial cells: Oxidative stress, proinflammatory response and mitochondrial dysfunction. Environ. Int. 2016, 89, 30-37. [CrossRef]

49. Li, S.; Li, B.; Jiang, H.; Wang, Y.; Qu, M.; Duan, H.; Zhou, Q.; Shi, W. Macrophage depletion impairs corneal wound healing after autologous transplantation in mice. PLoS ONE 2013, 8, e61799. [CrossRef] [PubMed]

50. Bellner, L.; Marrazzo, G.; van Rooijen, N.; Dunn, M.W.; Abraham, N.G.; Schwartzman, M.L. Heme oxygenase-2 deletion impairs macrophage function: Implication in wound healing. FASEB J. 2015, 29, 105-115. [CrossRef]

51. Li, Z.; Burns, A.R.; Smith, C.W. Two waves of neutrophil emigration in response to corneal epithelial abrasion: Distinct adhesion molecule requirements. Investig. Ophthalmol. Vis. Sci. 2006, 47, 1947-1955. [CrossRef]

52. Marrazzo, G.; Bellner, L.; Halilovic, A.; Volti, G.L.; Drago, F.; Dunn, M.W.; Schwartzman, M.L. The role of neutrophils in corneal wound healing in HO-2 null mice. PLoS ONE 2011, 6, e21180. [CrossRef] [PubMed]

53. Li, Z.; Burns, A.R.; Han, L.; Rumbaut, R.E.; Smith, C.W. IL-17 and VEGF are necessary for efficient corneal nerve regeneration. Am. J. Pathol. 2011, 178, 1106-1116. [CrossRef] [PubMed]

54. Kim, J.-K.; Kang, H.-M.; Jang, D.-C.; Na, J.-K.; Choi, K.-Y. Effect of Light Intensity and Temperature on the Growth and Functional Compounds in the Baby Leaf Vegetable Plant Peucedanum japonicum Thunb. Hortic Sci Technol 2020, 6, 822-829.

55. Lim, H.; IKim Jeong, Y. Antioxidant activities of Peucedanum japonicum Thunberg root extracts. J. Korean Soc. Food Sci. Nutr. 2019, 1, 32-39. [CrossRef]

56. Liang, N.; Kitts, D.D. Role of chlorogenic acids in controlling oxidative and inflammatory stress conditions. Nutrients 2016, 8, 16. [CrossRef] [PubMed]

57. Roshan, H.; Nikpayam, O.; Sedaghat, M.; Sohrab, G. Effects of green coffee extract supplementation on anthropometric indices, glycaemic control, blood pressure, lipid profile, insulin resistance and appetite in patients with the metabolic syndrome: A randomised clinical trial. Br. J. Nutr. 2018, 119, 250-258. [CrossRef]

58. Salomone, F.; Galvano, F.; Volti, G.L. Molecular bases underlying the hepatoprotective effects of coffee. Nutrients 2017, 9, 85. [CrossRef] [PubMed]

59. Larsson, S.C.; Virtamo, J.; Wolk, A. Coffee consumption and risk of stroke in women. Stroke 2011, 42, 908-912. [CrossRef]

60. Mubarak, A.; Bondonno, C.P.; Liu, A.H.; Considine, M.J.; Rich, L.; Mas, E.; Croft, K.D.; Hodgson, J.M. Acute effects of chlorogenic acid on nitric oxide status, endothelial function, and blood pressure in healthy volunteers: A randomized trial. J. Agric. Food Chem. 2012, 60, 9130-9136. [CrossRef]

61. Meng, S.; Cao, J.; Feng, Q.; Peng, J.; Hu, Y. Roles of chlorogenic acid on regulating glucose and lipids metabolism: A review. Evid. Based Complementary Altern. Med. eCAM 2013, 2013, 801457. [CrossRef]

62. Bagdas, D.; Etoz, B.C.; Gul, Z.; Ziyanok, S.; Inan, S.; Turacozen, O.; Gul, N.Y.; Topal, A.; Cinkilic, N.; Tas, S. In vivo systemic chlorogenic acid therapy under diabetic conditions: Wound healing effects and cytotoxicity/genotoxicity profile. Food Chem. Toxicol. 2015, 81, 54-61. [CrossRef] [PubMed] 